Beltrán Fortes, J., (2020): “El III Duque de Alcalá y sus intereses epigráficos. Notas sobre su colección lapidaria en Sevilla (Siglo XVII)", Spal 29.2: 259-279. DOI: https://dx.doi.org/10.12795/spal.2020.i29.26

\title{
EL III DUQUE DE ALCALÁ Y SUS INTERESES EPIGRÁFICOS. NOTAS SOBRE SU COLECCIÓN LAPIDARIA EN SEVILLA (SIGLO XVII)
}

\section{THE 3RD DUKE OF ALCALÁ AND HIS EPIGRAPHIC INTERESTS. NOTES ON HIS LAPIDARY COLLECTION IN SEVILLE (XVII CENTURY)}

\author{
JOSÉ BELTRÁN FORTES \\ Departamento de Prehistoria y Arqueología. Facultad de Geografía e Historia \\ c/ María de Padilla. Universidad de Sevilla, 1, E-41004, Sevilla \\ Catedrático de Arqueología \\ Correo-e: jbeltran@us.es D https://orcid.org. 0000-0001-5841-4140 \\ ResearchID: https://publons.com/researcher/AAA-1575-2020
}

\begin{abstract}
Resumen: En los primeros decenios del siglo XVII Fernando Enríquez de Ribera (1583-1637), III duque de Alcalá de los Gazules, reformó la Casa de Pilatos, con la construcción de la biblioteca y armería, así como de una gran sala (Camarín Grande). En ella realizaba las sesiones de una de las tertulias o academias más importantes de Sevilla, a la que asistían pintores, poetas y anticuarios; entre ellos destacan Francisco Pacheco, Juan de Arguijo o el erudito Rodrigo Caro. La colección es conocida por diversos inventarios, realizados entre 1637 y 1642 . El duque tuvo asimismo sus intereses eruditos y fue coleccionista de antigüedades. Se analiza en este trabajo su lapidario o colección epigráfica; en concreto, tres copias modernas de inscripciones romanas de Tarragona, elaboradas en pizarra, el pedestal isíaco de Acci (Guadix), así como dos pedestales honoríficos de Siarum (Utrera) y de Hispalis (Sevilla). Fernando Enríquez asimismo realizó un estudio sobre la inscripción y relieves del citado pedestal de Guadix, que le había regalado el III marqués de Estepa, Adán Centurión, otro noble andaluz interesado por las antigüedades y su estudio.

Palabras clave: Historiografía; siglo XVII; epigrafía hispanorromana; Hispalis; Tarraco; Isis.
\end{abstract}

\begin{abstract}
In the first decades of the $17^{\text {th }}$ century Fernando Enríquez de Ribera (1583-1637), $3^{\text {rd }}$ Duke of Alcalá de los Gazules, reformed the Casa de Pilatos, constructing a library and an armory, as well as a large chamber (Camarín Grande). Sessions were periodically held here, creating one of the most important literary and academic gatherings in Seville, attended by painters, poets and art collectors; among them, Francisco Pacheco, Juan de Arguijo and the antiquarian Rodrigo Caro. The Duke also had his antiquarian interests and was an important antique collector. Inventories of his collection were made between 1637 and 1642 . This work analyses the lapidary or epigraphic pieces; in particular three modern copies carved in slate of Roman inscriptions from Tarragona, the Isis pedestal from $\mathrm{Acci}$ (Guadix), as well as two honorary pedestals from Siarum (Utrera) and Hispalis (Seville). Fernando Enríquez also produced a study on the inscription and reliefs of the pedestal from Guadix, which was given to him by the $3^{\text {rd }}$ Marquis of Estepa, Adán Centurión, another Andalusian nobleman interested in antiquities and their study.
\end{abstract}

Keywords: Historiography; XVII century; Spanish-Roman Epigraphy; Hispalis; Tarraco; Isis. 


\section{INTRODUCCIÓN}

El reciente estudio que hemos llevado a cabo sobre dos estatuas modernas, elaboradas hacia mediados del siglo XVI en Italia por encargo del I duque de Alcalá de los Gazules, Per Afán de Ribera III (1509-1571), que decoraron sendos ninfeos en el jardín del palacio de los Enríquez de Ribera, en la localidad de Bornos (Cádiz) (Beltrán y Loza en prensa, 2020: 317-321, nos 255-256), me ha llevado a revisar esa importante colección arqueológica. El aristócrata sevillano adquirió las esculturas de la colección en Italia y las instaló tanto en Sevilla, en la llamada Casa de Pilatos (Lleó 1998, 2018), como en Bornos, en el referido palacio. La serie de estatuas antiguas - de procedencia italiana, como se ha dicho- fue una de las colecciones nobiliarias más importantes de la España del Renacimiento (Trunk 2002). Así lo reconocía a fines de aquel mismo siglo XVI Diego de Villalta en su Tratado de las antiguedades de la memorable Peña de Martos (1590), al destacar las tres colecciones más importantes a su juicio de escultura antigua en España, con piezas romanas traídas desde Italia: la de Diego Hurtado de Mendoza, la del marqués de Mirabel, Luis de Ávila y Zúñiga, y la de nuestro I duque de Alcalá (vid. por ejemplo Morán 2010: 17, Di Dio y Coppel 2013: 121-122 [Mirabel], 122-123 [Alcalá] y 125-132 [Mendoza]).

Son sobresalientes los estudios sobre las esculturas antiguas de la Casa de Pilatos realizados por Markus Trunk (2001, 2002, 2013, en prensa), a los que se añaden los trabajos más generales de Vicente Lleó, incluyendo extensas referencias a la Casa y a las colecciones pictóricas; asimismo, ha analizado la figura del III duque de Alcalá, Fernando Enríquez de Ribera y Téllez-Girón (1583-1637) (Lleó 1987, 1998, 2017), otro importante coleccionista, sobre el que trataremos en esta ocasión. El afán colector de este III duque derivó a lo largo de su vida desde las antigüedades hacia el ámbito de la pintura, algo habitual en la nobleza española del XVII (Morán y Checa 1985: 179-212), conformando una importante colección de cuadros en el palacio sevillano de la Casa de Pilatos, que posteriormente se dispersó en gran parte (Brown y Kagan 1987). No obstante, sus intereses eruditos y anticuarios también lo hacen sobresalir dentro de la alta nobleza española. Así, el anticuario utrerano Rodrigo Caro apuntaba que: «Entre las quales casas es insigne la de los Excelentissimos Duques de Alcala: porque demas de su raro edificio, en ella han juntado sus dueños muchas efigies de marmol de Principes, y varones insignes antiguos, y dos grandes Colosos de la diosa Palas, y otra multitud de estatuas, y despojos de la antiguedad: y el Excelentissimo Duque don Fernando Enriquez Afan de Ribera, que oy possee esta casa, ha juntado una gran Librería, $y$ en ella tantos volumenes de todas ciencias, y letras humanas manuscritos, y medallas antiguas, que compite con las mas insignes del mundo»(Caro 1634: 63v).

\section{EL III DUQUE DE ALCALÁ. POLÍTICA Y ERUDICIÓN EN LOS PRIMEROS DECENIOS DEL SIGLO XVII}

\subsection{Apuntes biográficos y de formación}

Al estudio biográfico, ya clásico, que Joaquín González (1969) dedicó al III duque de Alcalá, se unen recientemente los interesantes trabajos de David Mallén, dentro de una valoración general de los aspectos coleccionistas y eruditos del personaje, en el marco de su tesis doctoral (Mallén 2016, 2017, 2018a, 2018b). Hay que destacar, sobre todo, la documentación de archivo referida a los bienes del duque; en primer lugar, el inventario realizado sobre piezas localizadas en la Casa de Pilatos a poco de la muerte del duque, en 1637, con indicación de los lugares en los que estaban, que es el más completo, y que ya fue dado a conocer por J. Brown y R. Kagan (1987). En segundo lugar, los nuevos documentos recuperados por D. Mallén (2017) que incluyen el inventario de piezas ante el embargo de las propiedades del III duque a su muerte, asimismo realizado en 1637; la relación manuscrita de piezas que rescataba el VII duque de Medinaceli en 1639, cuando tras la muerte de la hija del III duque, María -casada con el príncipe de Paternò-, su esposa se convirtió en la nueva heredera, la V duquesa de Alcalá; así como la enumeración de las almonedas de los años 1640 y 1642; y, finalmente, varios informes de envíos, robos y pérdidas de piezas, realizados en 1641 .

La biografía del duque es propia de la alta nobleza española de la época de los Austrias a caballo entre los siglos XVI y XVII, cuando España dominaba el mundo y su aristocracia era altiva, rica, culta y erudita; también de Andalucía procedían nobles de ese talante, como, por ejemplo, el duque de Medina Sidonia, el marqués de Zahara, el conde de Gelves, el marqués de Mondéjar o el duque de Arcos (Morejón 2009: 229), a los que habría que sumar el marqués de Estepa (Ballesteros 2002), a quien nos referiremos más adelante. Es bien conocida la tradición coleccionista y erudita de los Alcalá, sobre todo, del I duque, el ya citado Per Afán de Ribera, y del padre del III duque, el IV 
marqués de Tarifa (1565-1590), quien murió a los 25 años, sin acceder al ducado; este segundo protagonizó una importante tertulia sevillana en la finca suburbana de Huerta del Rey (Rodríguez Marín 1903). Francisco Pacheco cuenta la anécdota de que su preceptor, Francisco de Medina (1544-1615), discípulo a su vez de Juan de Mal Lara y que estuvo un tiempo en Italia, entre 1564 y 1570, se retiró de la vida pública desilusionado por la temprana muerte de su pupilo; relata que: «Esta muerte del Marques de Tarifa fue al prudente varón causa de retirarse, dexando la catedra de San Miguel i la pompa de palacio, en lo mas apartado de los arrabales desta ciudad a vida quieta, donde dispuso un riquíssimo museo de rara librería y cosas nunca vistas de la antigüedad i de nuestros tiempos» (Pacheco 1985: 140; vid., López Rodríguez 2010: 46-47), aunque posteriormente fue secretario del arzobispo de Sevilla, Rodrigo de Castro. A la muerte del IV marqués de Tarifa su hijo Fernando solo tenía siete años y su madre y tutora Ana Girón de Guzmán, hija del duque de Osuna, se trasladó con la familia al palacio de Bornos. Allí estuvo cuatro años, hasta 1594, en que se aposentaron en Sevilla, ocupando la Casa de Pilatos. En 1597, con solo 14 años, participó junto al duque de Alba en la defensa de Cádiz contra la armada inglesa, y ese mismo año se casó con Beatriz de Moura, hija del I marqués de Castel-Rodrigo.

\subsection{La tertulia de la Casa de Pilatos}

Con la llegada del nuevo siglo XVII Fernando Enríquez accedió al mayorazgo ducal, en pleito con su madre, y comenzó a reformar la Casa de Pilatos, en unas obras que ejecutará Juan de Oviedo, arquitecto y maestro mayor de Sevilla. Destaca la construcción de la estancia para la tertulia o academia, denominada como Camarín Grande, con dos "retretes" o estancias menores a cada lado (Lleó 2017: 137-148, 162-163, 167, Mallén 2018b: 392-395); el techo lo pintó Francisco Pacheco en 1603, con el asesoramiento del ya citado F. de Medina y del racionero cordobés Pablo de Céspedes (Rubio 1993), discípulo de Ambrosio de Morales y asiduo de Sevilla y Roma (Pacheco 1985: 99-104). La pintura representaba la "Apoteosis de Hércules" y seguía la que dos años antes había ordenado pintar Juan de Arguijo en la estancia de su casa donde asimismo celebraba su correspondiente tertulia (López Torrijos 1999, Peñalver y Loza 2017). La estancia es el actual "Salón Pacheco" de la Casa de Pilatos.

Ambas tertulias, la de Alcalá y la de Arguijo, junto a la del propio Francisco Pacheco, serán las más destacadas de la ciudad de Sevilla, considerada como una "Nueva Roma" (Lleó 1979), en unos momentos en que triunfaba el estudio, colección y veneración de la antigüedad clásica y de las antigüedades (Méndez Rodríguez 2005: 201ss.). Sobresalieron, entre los siglos XVI y XVII, «las siguientes Academias sevillanas... la del conde de Gelves, la de Juan de Mal Lara, la de Juan de Arguijo, la de Francisco Pacheco, la de Argote de Molina y, sobre todas ellas, la del Duque de Alcalá» (Lleó 1979: 68). Según describe Rodrigo Caro en su manuscrito sobre Varones insignes en letras naturales de la ilustrisima ciudad de Sevilla, a propósito de la celebrada en la Casa de Pilatos:

Era un Palacio frequentado siempre de los más doctos hombres que havia en Sevilla... y las conversaciones que en el se trataban solo eran disputas, y argumentos de Letras. Siempre que salía de su Casa [el III duque] ... yendo à recrearse llevaba consigo en su coche sus libros y hombres doctos con quien conversar, y mas parecia su Casa Academia que Palacio de gran Señor (Caro sin fecha: 145v; también lo reproduce Montoto 1915).

Conformaban reuniones de poetas, pintores - ut pictura poesis-y eruditos, todos estudiosos de la Antigüedad y de sus restos, junto a los nobles mecenas, que compartían las mismas aficiones. El propio III duque de Alcalá escribió, en 1619, una disertación bajo el nombre Del título de la Cruz, donde analizaba la inscripción grabada en la cruz de Cristo, así como defendió que fue sujeto con cuatro clavos y no con tres (Brown y Kagan 1987: 234). Lo cita el cronista sevillano Diego Ortiz de Zúñiga (1636-1680):

Don Fernando Afan de Ribera, Duque de Alcalá, hasta en las letras y erudicion grande, escribio un erudito trabajo del título de la Cruz, y otro sobre la opinion de haber sido Christo Señor nuestro crucificado con quatro clavos, é hizo dar á la imprenta el Viage de Jerusalen, que escribió é hizo el Marques primero de Tarifa Don Fadrique... (Ortiz de Zúñiga 1796: IV, 174).

Ello ocasionó cierta polémica, en especial con el racionero de la Catedral de Sevilla Francisco de Rioja, que posteriormente fue secretario del conde-duque de Olivares (Mallén 2018b: 399). A la tertulia de la Casa de Pilatos asistían los ya citados F. de Medina de nuevo vinculado a los Alcalá-, J. de Arguijo, F. de Pacheco, el poeta Juan de Jáuregui, así como, en sus estancias sevillanas, el cordobés Pablo de Céspedes quien tenía casa en la ciudad hispalense (López Rodríguez 2010: 49)- o el impresor flamenco Francisco 
Heylan (Mallén 2018b: 400ss., con bibliografía anterior). De manera esporádica formaría parte ya de esa tertulia el joven Rodrigo Caro, que se convertirá en el erudito más importante del círculo sevillano en la primera mitad del siglo XVII e incorporaba su experiencia en el campo anticuario. No era el único aficionado a la Antigüedad en la tertulia; además del ya indicado interés de Francisco de Medina por las antigüedades, también Juan de Arguijo (1567-1623) conformó una biblioteca y colección escultórica en su casa sevillana de la calle Compañía, seguramente imitando a la de los Alcalá en la Casa de Pilatos, aunque en un tono mucho menor. Así, tuvo una galería de viri antiqui, con bustos de emperadores romanos, y dos estatuas de mármol de Carrara elaboradas en talleres genoveses, que representaban a Meleagro y a Venus con Cupido. Alababa estas estatuas Lope de Vega en un soneto dedicado a J. de Arguijo, su amigo y protector: "Quien dice que fue Adonis convertido / en flor de lirio, y Venus en estrella, no vio, señor don Juan, la imagen bella que a España habéis de Génova traído» (López Torrijos 1999: 187, soneto CXX). La referencia a Adonis se justifica porque se pensaba entonces erróneamente que una de las estatuas genovesas de Arguijo lo representaba, cuando en realidad era a Meleagro. Como hemos argumentado en otras ocasiones, es posible que en su colección estuvieran al menos dos inscripciones romanas: el pedestal dedicado a Vesta Augusta (CIL II 1166), traído desde Cantillana, donde se sitúa la ciudad romana de Naeva, y el pedestal dedicado a L. Horatius Victor (CIL II 1166), de la propia Hispalis (Sevilla) (Beltrán 2017a: 141-145, 2017b: 70-72).

Personaje destacado de la tertulia será el citado anticuario Rodrigo Caro (1573-1647), quien se licenció en la Universidad de Sevilla en el año 1596. Una vez ordenado sacerdote, residió en su ciudad natal de Utrera, aunque siempre mantuvo relación con Sevilla, en la que ocupó una capellanía en 1615; completó su carrera eclesiástica como censor de libros (1619) y letrado de cámara (1621), así como - ese mismo año, o incluso el año anterior-visitador general de parroquias y conventos de monjas fuera de Sevilla, bajo el mandato del arzobispo Pedro Vaca de Castro; desarrolló hasta su muerte otros cargos eclesiásticos en el arzobispado y el Santo Oficio (Beltrán 2009). Desde 1627 vivió en Sevilla de manera más estable, trasladando parte de la colección arqueológica que había formado en Utrera. Aquí su colección estaba en una finca rural, llamada "la Maya", donde quizás tuvo un jardín arqueológico; la colección se componía de inscripciones, esculturas, pequeños objetos (ladrillos, lucernas, lacrimatorios, urnas o vidrios, hallados en tumbas romanas) (Montoto 1915: 125-126, Morales 2006: 235-256) y monedas, aunque destacaban una estatua y cuatro cabezas romanas, así como más de una docena de inscripciones latinas. No obstante, solo son conocidas por las referencias que sobre ellas recoge el mismo Caro en sus escritos (Montoto 1915: 109-155, Morales 2006: 241-253, López Rodríguez 2010: 75-78). Se trata de una típica colección de erudito de la época, con predominio de monedas e inscripciones, que sirven para los propios estudios sobre la antigüedad romana. Las primeras visitas a Itálica le incitaron a escribir el famoso poema Canción a las Ruinas de Italica, que comenzó en 1595 y, tras diversas versiones, terminó en 1614. Entre sus obras más eruditas de contenido arqueológico y epigráfico, que fueron impresas en vida o quedaron inéditas, hay que referir el Memorial de la Villa de Utrera (1604), las Inscripciones y Antigüedad de Utrera (1622), las Inscripciones antiguas del arzobispado de Sevilla vistas en los años 1621-1625 y las Antiguedades de Sevilla (Caro, 1634), con sus Adiciones, inéditas. Sus primeros trabajos sobre las inscripciones y antigüedades de Utrera demuestran que ya conocía de primera mano la colección de la Casa de Pilatos (Brown 1995: 49).

\subsection{La biblioteca del duque}

Fernando Enríquez también mandó construir en la casa de Pilatos, desde 1604, sendas estancias para armería y biblioteca, que situó por encima del que había sido guardarropa de su tío abuelo, el I duque de Alcalá, abierto al Jardín Grande (Lleó 2017: 136ss.); posiblemente se terminó la construcción en 1617. El incremento importante de libros de la biblioteca se produjo en 1606 , con la compra de la que había sido la colección de Luciano de Negrón, examinador de libros en la Inquisición y que tenía ejemplares que habían sido propiedad de Ambrosio de Morales; su biblioteca contaba con unos 5000 volúmenes (Lleó 2017: 154-155). Se congratulaba F. Pacheco de que la magnífica colección de libros de Negrón «viniesse a manos de un tan docto $i$ esclarecido príncipe como don Fernando Enríquez de Ribera, tercero Duque de Alcalá» (Pacheco 1985: 135, Méndez Rodríguez 2000, López Rodríguez 2010: 47-48). A la muerte del III duque, en 1637, la biblioteca de la Casa de Pilatos constaba de 6500 volúmenes, algunos de los cuales los había enviado desde Nápoles, donde estuvo como virrey entre 1629 y 1631, y de donde envió asimismo armarios con gavetas para la colección de monedas y medallas 
(Brown y Kagan 1987: 248-255, Mallén 2018a: 263264). Algunos de esos armarios, junto a otros, se incluyen en los dos inventarios de bienes realizados en 1637, recogidos por J. Brown y R. Kagan (1987) y por D. Mallén (2017). En este último trabajo se transcribe:

Un caxón de madera tosco y dentro del un escriptorillo de ébano con dies y seis gavetillas y en cada una de ellas algunas monedas la mayor parte dellas asentadas en guarniçión de ébano y otras sin ella y las dhas monedas son de bronçe y otros metales q[ue] se pudieron reconoçer, solo se reconoçió una el pareçer forma de en medio Jastón de Portugal. $-Y$ en el dho caxón otro escriptorillo aforado en quero arxentado con unos perfiles de oro y en seis gavetillas parece ay otras medallas como las que quedan referidas y diferentes hechuras y metales. -Otro escriptorillo de ébano con perfiles, baçío. -Otro escriptorillo de nogal, bacío... -Otro escriptorillo a manera de escribanía de ébano con otras monedas. -Una caxetilla de madera blanca pequeña con otras monedas como las que quedan dhas arriba (Mallén 2017: 124).

A la biblioteca también se refirió José Gestoso (1910 241-244), aunque confunde al abuelo -el II duque de Alcalá-, con el nieto, el III duque. Posteriormente, a comienzos del siglo XVIII, una vez que la Casa Ducal de Alcalá se había integrado en la de Medinaceli, el deán de Alicante Manuel Martí catalogará la biblioteca, contabilizando unos 6000 volúmenes; aprovechó su estancia en Sevilla para documentar piezas destacadas de la colección arqueológica (Beltrán 2003: 48-51).

En el inventario post mortem realizado para el embargo de los bienes del III duque se describe la biblioteca de la siguiente manera:

\begin{abstract}
...en la cassa librería del dho señor duque, y en ella en los estantes en que ay duçientas y sesenta divisiones para que ubo seis mil y quinientos cuerpos de libros grandes y pequeños, de diferentes xeneros y materias y diferentes enquadernaçiones... Y asi mismo en la dha librería ensima de los estantes della ay algunos basos de diferentes calidades y hechuras y barros y en ellos algunas pinturas y labores (Mallén 2017: 124).
\end{abstract}

No sabemos a qué clase de vasos se referían y si eran cerámicas antiguas, aunque es probable que hubiera alguna. También poseía el III duque una importante colección de pequeños bronces, de tema mitológico, que llegaban casi al centenar. Entre ellos se incluían seis del artista italiano Giambologna, o al menos de su taller: un jabalí, un león, una Venus púdica, un hombre con otra figura a los pies, Hércules y Anteo y un rapto de las Sabinas (Mallén 2016). Los bronces estaban colocados en el Camarín Grande (Brown y Kagan 1987: 253ss.). Como sintetizan M. Morán y F. Checa, siguiendo a V. Lleó (1979: 65), en la biblioteca, aparte de los libros, «aparecian inscripciones, medallas, anillos, cuadros, estatuas, monedas, esferas armilares, reliquias -como la urna con las cenizas de Trajano y la cabeza de barro de don Pedro-y la habitual galería de retratos de hombres ilustres» (Morán y Checa 1985: 155).

\subsection{Avatares vitales y políticos}

El duque desempeñó su primer gran cargo público, el virreinato de Cataluña, entre 1618 y 1622, aunque salió de Sevilla en 1619; con ello se interrumpieron las actividades de la tertulia en esos cuatro años. Posteriormente, en 1625 será nombrado por el rey Felipe IV embajador en Roma ante el Papa Urbano VIII, donde estuvo hasta 1626 (Brown y Kagan 1987: 234-235). Felipe IV había visitado Andalucía en 1624 y Alcalá produjo una buena impresión en el joven rey y en su valido Olivares.

Sería en esos años entre 1622 y 1625 , residiendo en Sevilla, aunque con alguna estancia en Madrid, cuando se desarrolló su afición a las antigüedades (Mallén 2018b: 401ss.), sobre todo, por influencia posiblemente del ya citado Rodrigo Caro. Este le dedica al duque su obra sobre las Inscripciones y Antiguedad de Utrera (1622), indicando en el prólogo que había sido un encargo del aristócrata:

Los días pasados (Excmo. Señor) me mando V.E. le sirviese, trasladando las inscripciones antiguas, que en esta Villa de Utrera ay, diligencia que luego puse en execución, aunque por la ausencia de V.E. no las he embiado. Aora lo hago acompañando con ellas unas breves notas, que de su antigüedad he observado (Caro 1622: 2r).

Esa relación entre el duque y Caro queda en evidencia también en su obra Dias Geniales o Ludricos, en la que, en forma de diálogos, tres caballeros discuten sobre los juegos en la Roma antigua, a propósito de una inscripción romana que están analizando (Caro 1978, con el estudio modélico de J.-P. Etienvre). El marco es un jardín a las afueras de Sevilla: se ha dicho que sería una trasposición de su finca "la Maya", en Utrera, siendo Caro por tanto el propietario, experto en epigrafía, y que explica temas de Antigüedad a sus dos amigos, don Diego y don Pedro (Domergue y Étienvre 1971). Parece verosímil esa identificación, pero curiosamente el propietario del jardín se llamaba 
don Fernando y al III duque está dedicado el libro, por lo que quizás a éste mejor represente el don Fernando de la ficción; no hay que olvidar que también los Alcalá tenían una finca de recreo cerca de la Buhaira -más cercana a Sevilla que "la Maya", por tanto-, en donde el grupo de tertulianos de la Casa de Pilatos celebraba de tanto en tanto alguna reunión.

En aquellos años también asistirá a la renovada tertulia del duque otro coleccionista de antigüedades, el oidor Sancho Hurtado de la Puente, a quien R. Caro había alquilado una casa en Sevilla, en la que instaló parte de su colección, y del que era buen amigo. A él va dirigida la carta que Caro escribe en Utrera el 25 de junio de 1627, explicando detalles de su colección conservada en "la Maya", «con las inscripciones fijas en la pared», así como del traslado de parte de ella a la casa alquilada en Sevilla (Montoto 1915: 155, López Rodríguez 2010: 77). Tras la muerte del III duque, se les encomendó a los pintores Francisco de Zurbarán y Francisco Herrera el Viejo la tasación de la colección de cuadros y estampas, así como al escultor Juan Martínez Montañés la de las esculturas y, precisamente, a Rodrigo Caro la de monedas y medallas, terminándose esa valoración solo en marzo de 1641 (Mallén 2017: 118). En una carta del III marqués de Estepa al erudito malagueño Martín Vázquez Siruela, fechada el 28 de agosto de 1647, le dice: «...muchas [monedas] solia tener el Duque de Alcala que no se ahora en poder de quien paran» (carta reproducida en Ballesteros 2002: 214).

Tras la embajada extraordinaria desempeñada en Roma entre 1625-1626, el duque volvió a Sevilla a la espera de otros cargos. Fue nombrado gobernador de Milán (1627), pero no llegó a trasladarse, pues en 1628 el rey le concedió el importante virreinato de Nápoles. En el desempeño del cargo tuvo enfrentamientos con el anterior virrey, el IV duque de Alba, que era cuñado del conde duque de Olivares, valido del rey. Se conserva de aquella época una medalla conmemorativa en bronce en la que aparece su retrato en el anverso, a la manera clásica -«como en ocasiones acostumbraron los antiguos»-, y en el reverso la representación de la diosa Astrea, diosa de la justicia, que conmemora sus reformas legislativas; fue diseñada en 1630 por el italiano Giulio de Grazia (Mallén 2016: 308, 2018a: 258, nota 54, Fernández Lacomba 2008). Pero aquel mismo año el duque de Alba, de nuevo en Nápoles como acompañante de la infanta María, la hermana del monarca español, en viaje para el matrimonio con el rey de Hungría, le acusó de un agravio a la infanta; Alcalá tuvo que trasladarse a Madrid al año siguiente a rendir cuentas en la corte, dejando el cargo (Ortiz de
Zúñiga 1796: tomo IV, 347ss.). Tras diversos avatares, consiguió de nuevo el favor regio y fue nombrado virrey de Sicilia en 1632; además, en 1636, Felipe IV le encomendó su representación en el congreso de Colonia, pero murió en el viaje para ese encargo, en la localidad austríaca de Villach, el 4 de abril de 1637.

Tal como se inició su vida, con la muerte de su padre cuando contaba siete años y de su abuelo cuando contaba once, así la muerte también empañó su final, pues, según recuerda Vicente Lleó:

Los últimos años de su vida fueron particularmente dramáticos, pues casi todos sus hijos, tanto legítimos como ilegítimos, le precedieron en el camino del sepulcro, con la única excepción de su hija María, casada con el Príncipe de Paternò, quien, sin embargo falleció sólo dos años después que su padre, sin dejar descendencia (Lleó 2017: 129).

En efecto, el hijo primogénito, VI marqués de Tarifa, aficionado a las letras como su padre y su abuelo, murió a los 19 años, en 1633, sin descendencia, así como también murieron las hermanas Margarita y Juana. Sobre el joven heredero refirió Diego Ortiz de Zúñiga (1796: IV, 174-175): «...imitando en todo á su padre, mostró gran inclinación á las letras, é imprimió en octavas la Fábula de Mirha. Murió en Palermo con infeliz malogramiento, gobernando su padre Virey el Reyno de Sicilia».

Muerta también la hija María sin descendencia, el título ducal recalará en 1639 en una sobrina del III duque, Ana María Luisa Enríquez de Ribera, que en 1623 había casado con el primogénito de la Casa de Medinaceli, Antonio Juan Luis de la Cerda (1607-1671). Así, el hijo de ambos, Juan Francisco de la Cerda Enríquez de Ribera (1637-1691), será, entre otros títulos, VIII duque de Medinaceli, VI duque de Alcalá de los Gazules y IX marqués de Tarifa, con lo que el mayorazgo de los Alcalá se diluyó en esta otra gran casa nobiliaria, asentada en Madrid. Con ello se inició la decadencia de la Casa de Pilatos (Lleó 2017: 191ss.), dando fin a aquellos esclarecidos representantes de una estirpe nobiliaria sevillana especialmente culta, aficionada a las antigüedades en varias generaciones durante el siglo XVI y primeros decenios del XVII.

\section{LOS INTERESES EPIGRÁFICOS DEL III DUQUE DE ALCALÁ}

Con base en el inventario ya referido que de la colección se hizo a su muerte (Brown y Kagan 1987), se ha 
hecho un reciente estudio sobre el lapidario del III duque de Alcalá (España-Chamorro, 2019), aunque está solo constreñido a algunas piezas. Así, recogeremos en este apartado otras piezas epigráficas de la colección, que amplían y complementan los afanes coleccionistas y eruditos del duque en el campo de las inscripciones antiguas. Según se apunta en ese último estudio, «en el ámbito arqueológico su interés [del III duque de Alcalá] se centró en algunas vasijas, en una amplia colección de monedas, en un vasto repertorio de escultura antigua y también en un lapidario epigráfico de interés» (España-Chamorro 2019: 73). No obstante, inmerso el III duque en los intereses eruditos propios de esa época manierista, a caballo entre el XVI y el XVII y que abre el siglo del Barroco, no se interesa tanto por las esculturas clásicas, sino por las monedas (o "medallas", como se las denominaba entonces), pequeños bronces, inscripciones y otros elementos arqueológicos, según hemos mencionado para la colección de R. Caro.

De las piezas epigráficas analiza Sergio EspadaChamorro un decempondium del praefectus Vrbi Q. Iunius Rusticus (CIL II 4962), que procedería de Roma; la inscripción sepulcral de Antonia Lais (CIL II 1211), grabada en una urna de plomo, de Gades (Cádiz); así como otras inscripciones sobre instrumenta domestica: una grabada sobre un vaso cerámico, de la que se concluye que es un texto interpolado o falso, otra segunda sobre un lingote de plomo, que se dice en el inventario que procede de Cartagena, y, finalmente, «cinco losetas de mármol antiguas con inscripciones de Sepulcro» (Espada-Chamorro 2019: 78) sin más precisión. Para estas últimas este investigador propone su identificación con otras cinco inscripciones relacionadas con la Casa de Pilatos, recogidas en CILA Sevilla 25, 113, 114, 125 y 141. Ello es factible solo para tres de ellas, que corresponden a placas sepulcrales referidas por R. Caro: la n ${ }^{\circ} 113$, que Hübner vio en Sevilla (CIL II 1221), la n 114, que había sido trasladada a Madrid, donde la documentó asimismo el epigrafista alemán (CIL II, 4982), y la $\mathrm{n}^{\circ} 125$, que ya Hübner no llegó a ver personalmente (CIL II 1242); pero no lo es para las otras dos, ya que la $\mathrm{n}^{\circ} 25$ es un pedestal de estatua, conservado aún en Sevilla, que mencionaremos más adelante, y la $\mathrm{n}^{\circ} 141$ es un altar sepulcral -de incorporación más reciente a la colección Medinaceli-, y que no se pueden lógicamente identificar como "losetas". Por el contrario, debe incluirse la inscripción CILA Sevilla 115, que sí corresponde a una placa sepulcral referida por Caro en la Casa de Pilatos y que luego fue trasladada a Toledo, donde ya Hübner tampoco la vio (CIL II 1230). Quizás quedaran solo ya solo cuatro placas funerarias, porque en el inventario del embargo a la muerte del duque, del mismo año 1637, se refieren: «Quatro loças pequeñas de piedra de letreros antiguos» (Mallén 2017: 124).

\subsection{Tres copias modernas de inscripciones de Tarraco (Tarragona)}

Piezas epigráficas singulares en la colección que se conserva actualmente en la Casa de Pilatos son tres inscripciones grabadas sobre placas de pizarra negra y que se exponen al público, junto a otros soportes epigráficos, así como piezas tardoantiguas y modernas, en una galería que abre hacia el llamado Jardín Chico (fig. 1).

$\mathrm{Su}$ excepcionalidad radica en que se trata de tres copias modernas de inscripciones romanas de Tarraco (Tarragona), que fueron adquiridas por el III duque de Alcalá durante los años en que fue virrey de Cataluña. Aunque fue nombrado oficialmente el 25 de agosto de 1618, partió de Sevilla el 30 de julio de 1619 y retornó el verano de 1622. La situación general de España y particular de Cataluña no era especialmente favorable; hay que recordar que en 1618 había comenzado la que se llamará "Guerra de los 30 Años", en la que España se vería involucrada, mientras que en 1621 acabó la "Tregua de los 12 años" contra los Países Bajos, acontecimientos que empeoraron la crisis económica, lo que repercutió además en el malestar en Cataluña. Aunque su estancia es anterior a las revueltas catalanas de los años siguientes, la situación era desfavorable para un gobierno virreinal sin enfrentamientos con los poderes locales (Elliot 1963: 127-155). Como bien indica Vicente Lleó:

Le tocó a Alcalá gobernar el principado en circunstancias sumamente difíciles y, pese a su evidente buena voluntad, no tardó en enemistarse prácticamente con todos los estamentos catalanes... el único alivio que el Virrey pudo encontrar durante estos años fueron sus excursiones, como erudito y coleccionista, a viejas abadías y yacimientos arqueológicos (Lleó 2017: 155-156)

En ese contexto adquirió el virrey para su colección sevillana las tres copias de las inscripciones, aunque no sabemos en qué circunstancias concretas. Ello quedó evidenciado ya en el inventario de 1637 , donde se dice que estaban colocadas en el Camarín Grande -es decir, la estancia con el techo pintado por Pacheco donde se reunía la tertulia o academia-: «Tres piçarras con letreros antiguos que trujo el Duque mi $s^{\text {or }}$ de Tarragona» (Brown y Kagan 1987: 254, $\mathrm{n}^{\circ}$ 140). Aunque no 


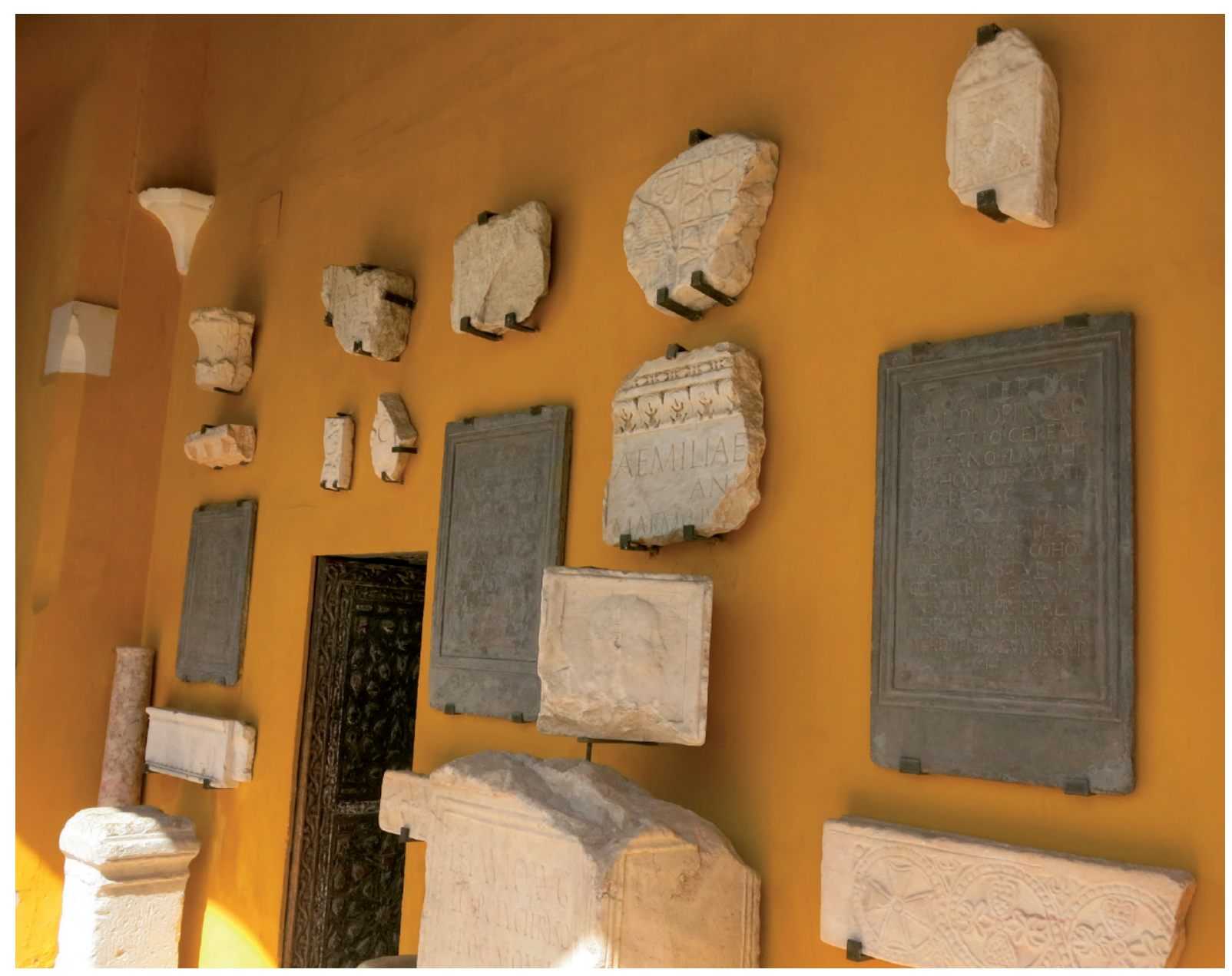

Figura 1. Restos arqueológicos y epigráficos en la galería junto al Jardín Chico. Casa de Pilatos, Sevilla.

se recogen en el segundo inventario de 1637, sí vuelven a aparecer citadas de manera más prolija en otro inventario de 1751, que fue dado a conocer por vez primera por el arqueólogo francés Arthur Engel (1903), pero con una ubicación distinta, en un

cuartico que sirve para piedras... está en la galería baja de la librería, haciendo frente a la habitación del jardinero... Tres piezas en tabla de pizarra la una de cuatro palmos y medio de alto y tres de ancho dedicadas á un tal Tempronio (sic), otra del mismo tamaño tambien con su inscripcion dedicada a un tal Valerio Propincuo y la otra de una vara de alto y tres cuartas de ancho con su inscripcion dedicada á Marco Calpurnio (Engel 1903: 267-268; cfr. Gestoso 1910: 263-164).

En efecto, las tres inscripciones son copias de las grabadas en otros tantos pedestales romanos de Tarraco:
1) Epígrafe dedicado a Marco Calpurnio Lupo, flamen provincial, cuya copia -de 83,5 × $62 \times 2 \mathrm{~cm}$ - dice (fig. 2): M · CALPVR · M · F / LVPO - FLAM. $/ \mathrm{P} \cdot \mathrm{H} \cdot \mathrm{C} \cdot \mathrm{EX}$ CONVEN / CAESAR $\cdot$ ERCAVIC / OMNIBVS · HONORIB / IN · REPVBLICA - SVA / FUNCTO - PRAEFECTO / COHORTIS - PRIMAE · / BITVRIGVM / P · H · C. En este caso las diferencias con respecto a la lectura de E. Hübner (CIL II 4203) son: M · CALPurnio m. $f$. (1. $\left.1^{\mathrm{a}}\right)$, LVpo flam (1. 2 $2^{\mathrm{a}}$, CONVENt $\left(1.3^{\mathrm{a}}\right)$, OMNIB (1. $\left.5^{\mathrm{a}}\right)$ y BITVRIgVM (1. $\left.9^{\mathrm{a}}\right)$, que derivaba de la lectura de Antonio Agustín, con dibujo reproducido en $C I L I^{2} / 14,1125$. Además, en este lugar se indica: «Exemplum novicium servatur Sevilla in Casa de Pilatos parieti adfixum, quod descripsi a. 1979 et iterum a. 1996», así como «exemplum novicium tacite suppletum (hand dubie inde scheda a Bosch saec. XIX facta, quae in Academia Berolinensi inter 


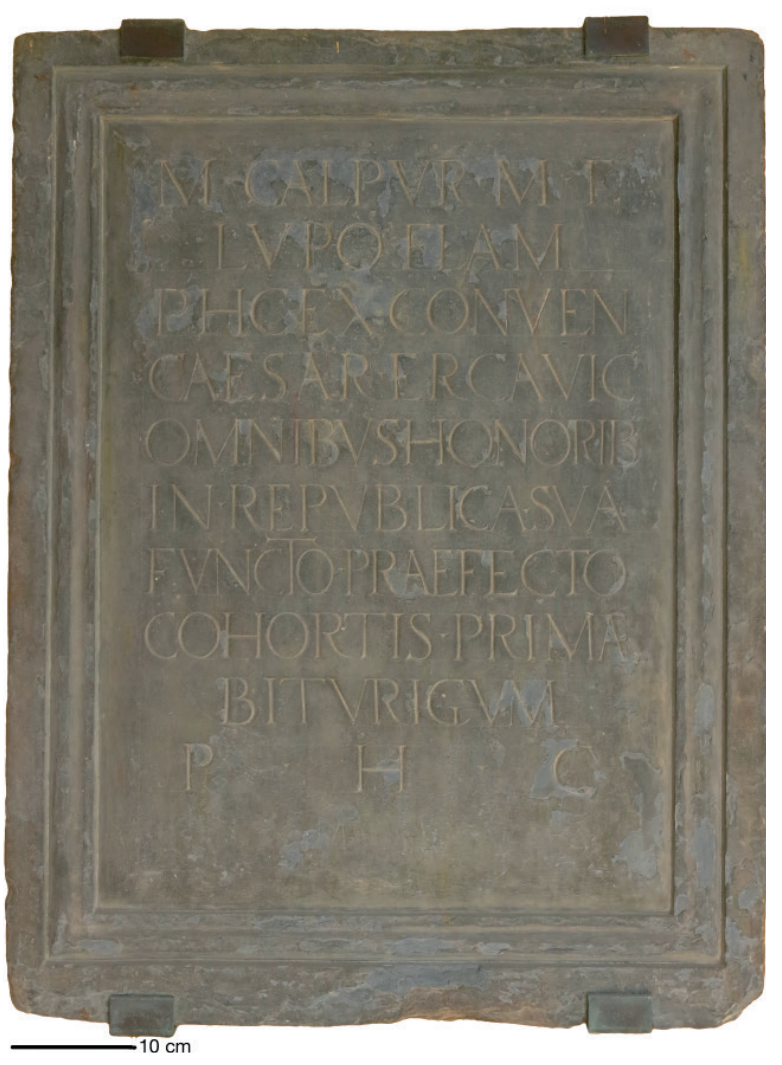

Figura 2. Copia del siglo XVII de la inscripción tarraconense de M. Calpurnio Lupo (CIL II 4203); pizarra (dimensiones: $83,5$ × 62 × $2 \mathrm{~cm})$. Casa de Pilatos, Sevilla.

schedas a L. Wickert collectas asservatur)». Las letras son capitales cuadradas de muy buena ejecución y cuidada ordinatio; puntos triangulares con vértice hacia abajo. Hay nexo de AE en PRIMAE $\left(1.8^{a}\right)$, y la $\mathrm{G}$ de la penúltima línea es grabada de manera incorrecta en la disposición del trazo vertical. Se aprecian perfectamente las líneas guía que se establecieron para la reproducción de la inscripción del original.

2) En la copia -de $95 \times 62 \times 2 \mathrm{~cm}$ - dedicada a Sempronia Placida dice la inscripción (fig. 3): SEMPRONIAE / FVSCI - F · PLACIDAE / POMPAELONENSI / FLAMINICAE - CON / SENSV $\cdot \mathrm{CONCILI} \mathrm{/} \mathrm{P} \cdot \mathrm{H} \cdot \mathrm{C} / \mathrm{C} \cdot \mathrm{CORNELIVS}$ - VALENS / MARITVS / S · P · F. En este caso la lectura es similar a CIL II 4246. La conservación del soporte es mala, habiendo saltado en muchos lugares la capa superficial de la pizarra. Está

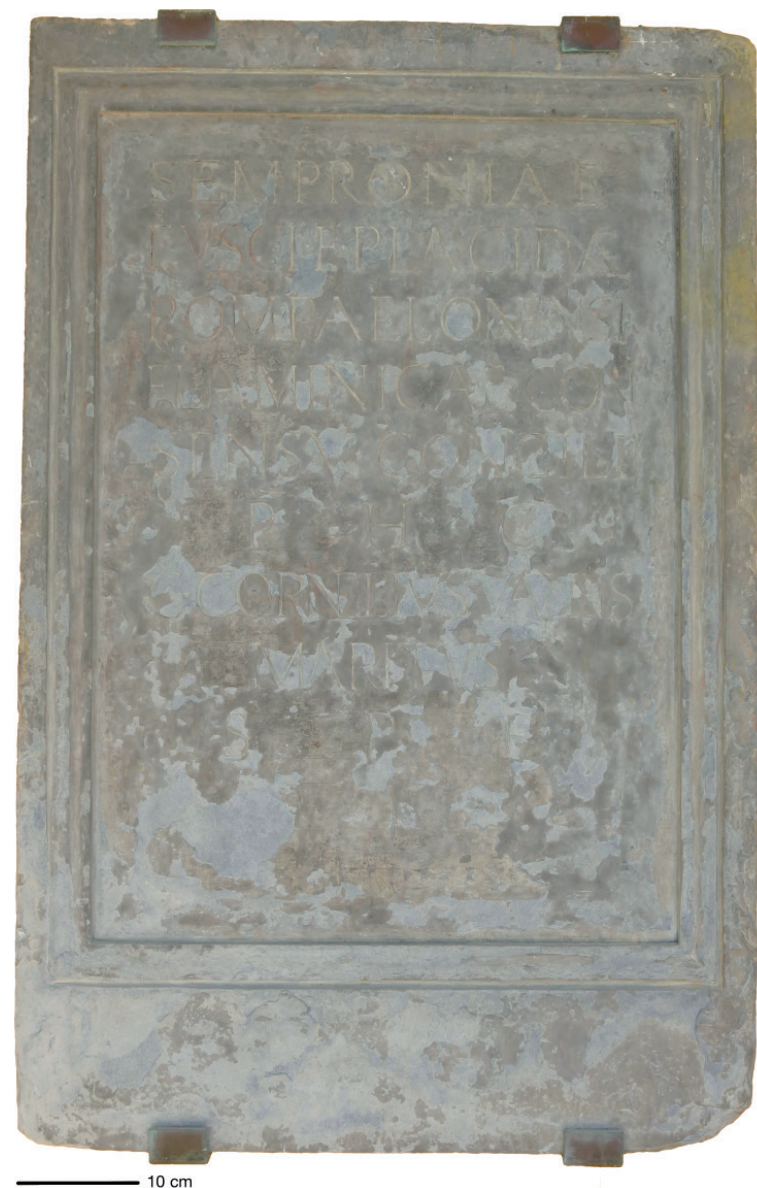

Figura 3. Copia del siglo XVII de la inscripción tarraconense de Sempronia Placida (CIL II 4246); pizarra (dimensiones: 95 x 62 x $2 \mathrm{~cm})$. Casa de Pilatos, Sevilla.

elaborada en letras capitales cuadradas de buena ejecución, realizadas con líneas guía. Hay nexo de AE en PLACIDAE (1. $2^{a}$ ), de NE en POMPAELONENSI (L. $3^{\mathrm{a}}$ ), así como de EN en VALENS (1. $\left.7^{\mathrm{a}}\right)$. Tanto Hübner como Alföldy $\left(C I L \mathrm{II}^{2} / 14\right.$, 1184) hacen referencia a este exemplum novicium. El marido asimismo aparece citado en otra inscripción tarraconense, dedicada hacia el 173 d.C. $\left(C I L \mathrm{II}^{2} / 14,1193\right)$.

3) Finalmente, la copia - de $95 \times 62 \times 2 \mathrm{~cm}-$ del pedestal dedicado a Valerio Propinquo dice (fig. 4): $\mathrm{M}$ - VALER · M · F / GAL · PROPINQVO / CRATTIO $\cdot$ CEREALI / EDETANO $\cdot$ FLAM $\cdot \mathrm{P} \cdot \mathrm{H} \cdot \mathrm{C}$ / CVI · HONORES · CIVITATIS / SVAE · RES - P $\cdot$ AC [ / ] T A ADLECTO - IN / EQVITE - A · $\mathrm{T} \cdot \mathrm{IMP} \cdot \mathrm{PRAEF} / \mathrm{FABR} \cdot \mathrm{BIS} \cdot \mathrm{PRAEF} \cdot \mathrm{CO}-$ HOR / SECVND · ASTVR · IN / GERM · TRIB · LEG · V • MAC / IN · MOESIA · PRAEF .

ISSN: 1133-4525 ISSN-e: 2255-3924 


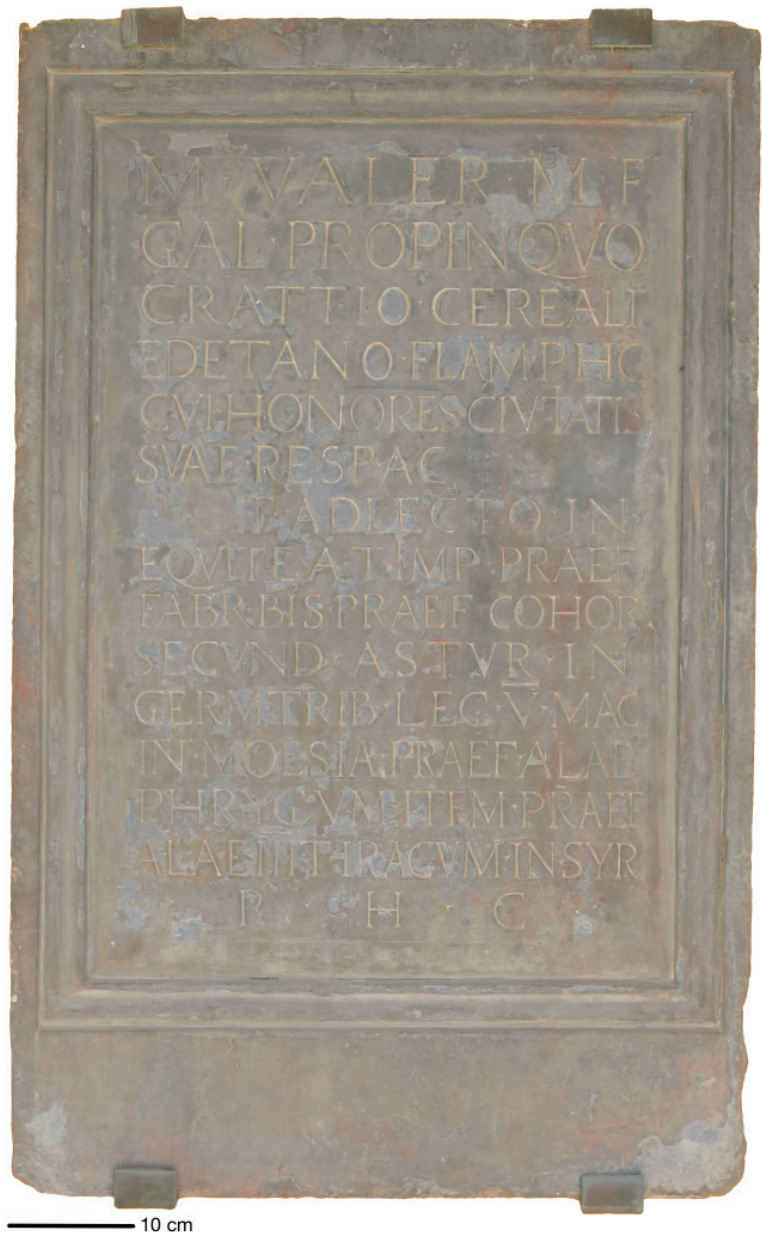

Figura 4. Copia del siglo XVII de la inscripción tarraconense de M. Valerio Propinquo (CIL II 4251); pizarra (dimensiones: $95 \times 62$ × $2 \mathrm{~cm}$ ). Casa de Pilatos, Sevilla.

ALAE / PHRYGVM · ITEM · PRAEF / ALAE · III $\cdot$ THRACVM $\cdot$ IN $\cdot \mathrm{SYR} / \mathrm{P} \cdot \mathrm{H} \cdot \mathrm{C}$. En CIL II 4251 se recoge esta lectura, pero sin el hueco existente en la copia al final de la $1.6^{\mathrm{a}}$ y el inicio de la $7^{\mathrm{a}}$, donde se grabaría GENIO / LVSIT, siguiendo la lectura de Antonio Agustín; además en 1. 14 $4^{\mathrm{a}} \mathrm{se}$ restituye como SYRia. En $C I L \mathrm{II}^{2} / 14,1171$ se corrige la lectura como: ACCIPERE (?) IN- / DULSIT (?); y en 1. 14 ${ }^{\mathrm{a}}$, SYR[ia]; de nuevo se refiere el «exemplum novicium non post saec. XVII prius factum, quod extat Sevilla in Casa de Pilatos, ubi recognovi a. 1996». La conservación es mejor que la de la pieza anterior, pero también tiene zonas donde ha saltado la capa superficial de la pizarra. Está elaborada en letras capitales de muy buena ejecución, con puntos triangulares y vértice hacia abajo. Además, están mal ejecutadas las $\mathrm{G}$ (11. $\left.2^{\mathrm{a}}, 10^{\mathrm{a}}, 12^{\mathrm{a}}\right)$, dispuesto erróneamente el trazo vertical, como en el primer exemplum; asimismo está mal realizado el nexo de TH en THRACVM $\left(1.14^{\mathrm{a}}\right)$.

Emil Hübner conoció los exempla novicia por referencia de Rodrigo Caro, según indica en ad CIL II 4251; no obstante, él solo llegó a ver dos piezas en la Casa de Pilatos, seguramente cuando visitó Sevilla en 1860:

...tituli aliquot servantur in palatio ducum de Alcalá olim, hodie de Medinaceli, quod la casa de Pilatos dicunt... Inter titulos ibi adhuc servatos (nonnulli enim originis externae Matritum esportati sunt in palatium ducum de Medinaceli) exempla novicia sunt titulorum Tarraconensium duorum, quos infra edemus, tabulis e lapide fissili inscripta (CIL II 154).

Nos parece que la razón del interés del III duque por las tres inscripciones radica en el elemento común que tienen, que es la relación con el concilium de la provincia Hispania Citerior, según quedaba en evidencia en la segunda de las piezas; en las otras dos, aunque no aparece el término concreto, estaba implícito. Por tanto, supondría para el virrey una referencia clara a la administración imperial romana, que en cierto modo era un antecedente a su política administrativa en Cataluña.

El interés por algunas de esas piezas queda en evidencia en la figura del propio Rodrigo Caro en sus $A n-$ tiguedades de Sevilla, cuando a propósito de defender «que era costumbre en los Conventos juridicos de España, tener una manera de Senado» (Caro 1634: 77v), argumenta «que en España hubo esta manera de gobierno... y que estavan en las cabeças de provincias, donde se juntaba el tal Concejo. Esto consta por varias inscripciones; $y$ en sola Tarragona, que fue cabeza de la Citerior, se hallavan tres, que pondremos aquí: una tiene estas letras» (Caro 1634: 78r), y a continuación reproduce la inscripción de Sempronia Plácida. A pesar de que contaba ya con el exemplum novicium ubicado en el Camarín Grande de la Casa de Pilatos, no respeta las líneas originales, que reduce a cinco, dándole una regular ordinatio editorial -pero ello es algo que hace en todos los casos, por criterios editoriales-. Ambrosio de Morales (1575: 69r) la editó en cuatro líneas, aunque sin olvidar que los elementos que en el libro de Morales en ocasiones "hermosean" las inscripciones son añadidos de la publicación, que nada tienen que ver con la realidad de los soportes, según se comprueba cuando estos se han conservado (en general, vid. Bonneville 1981). Rodrigo Caro tampoco recogió el praenomen del marido en su lectura, pero ello debió ser simplemente un error, en cierto modo comprensible, 
pues se repetían tres $\mathrm{C}$ seguidas; no se refiere este autor en el texto a que existía la copia en Sevilla, reproduciendo lo que Ambrosio de Morales decía de ella: «Es basa de estatua, que de consentimiento de toda la junta de la España Citerior, puso Cajo Cornelio Valente de su dinero a su mujer Sempronia Placida hija de Tusco, que avia sido Flaminica, y Sacerdotisa en Pamplona, o avia sido natural de alli» (Caro 1634: 78v).

El que la inscripción fuera citada por Morales, dentro del capítulo que dedica a Tarragona en Las Antiguedades de las ciudades de España (Morales 1575: 69r-v), debió de ser también un acicate que movió al III duque a encargar la copia de la inscripción. No sabemos por qué sumó las otras dos -en las que se refería a la $P$ (rovincia) H(ispania) C(iterior) como dedicante del honor-, y no otras, pero así ocurrió. Podemos especular que fue por razón de disponibilidad o de conservación de los textos, como hemos visto que sucede en el tercer ejemplo, pero realmente no lo sabemos. También desconocemos qué taller lo realizó o si se documentan otros ejemplos similares en el ámbito tarraconense; lo que sí parece plausible es que fueran ejecutadas por la misma mano, a lo que apunta las similares características formales de los soportes y las inscripciones. Destacamos la singularidad de los exempla sevillanos, en los que se supera la simple documentación escrita por el carácter monumental de la copia, acorde tanto con la erudición, cuanto con los intereses coleccionistas del noble y político sevillano.

No es un hecho único en la España de la Edad Moderna, ya que, aunque raras, en otras ocasiones asimismo se hicieron copias de inscripciones antiguas en soportes pétreos. Podemos destacar el caso del llamado "Arco de los Gigantes", de Antequera, construido en 1585 por el Cabildo antequerano en honor del rey Felipe II (Atencia 1993, Panzram 2009): se sustituyó la antigua puerta de la muralla islámica por una nueva de traza clasicista, con arcos de medio punto, decorada con inscripciones y esculturas (Loza y Romero 2014-2015). Así, se embutieron en la fachada exterior del arco inscripciones romanas que fueron recuperadas en la propia Antequera o trasladadas desde otras ciudades romanas cercanas, como Singilia Barba, Osqua, Nescania o Iluro. Sin embargo, en los casos en que no pudieron trasladarse los originales se copiaron los textos en soportes pétreos modernos, que ahora se conservan en el Museo Municipal de Antequera, adonde fueron llevadas a comienzos del siglo XX, cuando se desmanteló la puerta de sus antigüedades. Otro ejemplo, más avanzado en el tiempo, lo tenemos en la colección que Pedro Leonardo de Villacevallos conformó en Córdoba en los cuartos centrales del siglo XVIII (Beltrán y López 2003): de una placa opistógrafa que presentaba por una cara la inscripción romana de Postumio Aciliano y por la otra un epígrafe mozárabe se grabó la primera en un soporte nuevo, en letras capitales cuadradas que imitaban el texto latino; pero se incluyó en la parte baja una pequeña leyenda en castellano cursivo en que se dice que es una copia moderna, acorde con un sentido más científico propio ya de ese siglo ilustrado (Serrano y Atencia 1981: nº 11, lám. 19, Gimeno y Stylow 2003: 159).

\subsection{El pedestal de Isis de Acci (Guadix)}

Debemos detenernos también en una pieza bien conocida de la colección sevillana, por la singularidad del soporte y, de nuevo, de la inscripción: el famoso pedestal de la colonia Iulia Gemella Acci (Guadix), que soportaría una estatua de Isis y que presenta interesantes relieves en ambos laterales del cuerpo central (fig. 5.AC). Actualmente se encuentra en el Museo Arqueológico de Sevilla, por entrega en 1954 del entonces duque de Medinaceli desde la colección de la Casa de Pilatos, en donde se conservaba hasta aquel momento. Elaborada en mármol blanco, conserva unas dimensiones máximas de 87 x 47 x $47 \mathrm{~cm}$.

Lógicamente no voy a entrar ni en el análisis de la inscripción ni de los relieves, que ha motivado una amplia bibliografía, y remito especialmente al estudio de Jaime Alvar (2012: 119-124, n 168, especialmente 2016), que me parece muy ajustado y que aporta, sobre todo, una interpretación de las imágenes en relación con la inscripción, del agua sagrada que le proporciona a la difunta niña Avita el dios Abunis junto a Thot en forma de ibis, mientras en el otro lateral se dispone un pastor, el Hermes-Mercurio psicopompo, que lleva las almas al dios Apis-Osiris, en forma de toro; como concluye este autor «la excepcionalidad del monumento, adquiere dimensiones extraordinarias por lo revelador de la complejidad del culto practicado en Acci» (Alvar 2012: 123). También el análisis de la inscripción es complejo (vid., por ejemplo, CILA Granada 122); en primer lugar, por la pérdida del final de las primeras líneas, ya que el pedestal sufrió una doble reutilización: una profunda oquedad en la parte superior, cuadrangular, con un resalte para acoplar una tapadera, que creemos que es fruto de su reuso como pilar de una mesa de altar paleocristiana con loculus para las reliquias (Beltrán 1994), a pesar de que no porte la inscripción cristiana; y la pérdida de toda la parte superior derecha, que se haría con posterioridad. Está dedicada 
a Isis Puel[larum? -lari?] y la estatua la pone Fabia Fabiana, en honor de su nieta Avita, (ex) iussu dei $\mathrm{Ne}$ [tonis?]. En segundo lugar, por el extenso repertorio de joyas que se describe como regalo al templo isíaco para ornamentar a la diosa (Beltrán 2010). Ello trajo como consecuencia que ya prácticamente desde su descubrimiento en Guadix, en el año 1623, los eruditos de la época y posteriores centraran de manera habitual su atención sobre la pieza, generando una rica bibliografía anticuaria. A ella no nos vamos a referir, sino solo al hecho de que el propio III duque de Alcalá le dedicó un estudio, como ejemplo de su cultura e interés erudito por las antigüedades.

La historia de este pedestal nos acerca a otra importante familia nobiliaria andaluza con aficiones anticuarias y de coleccionismo epigráfico de la primera mitad del siglo XVII, los Centurión de Estepa. En concreto se trata de Adán Centurión y Córdoba (1582-1658), III marqués de Estepa, coetáneo del III duque de Alcalá; nació un año antes, aunque fue más longevo. Tenía el título de marqués del Aula o Laula, y en el año 1625 heredó el marquesado de Estepa a la muerte de su padre; se casó al año siguiente, en segundas nupcias, con su sobrina Leonor María Centurión, de la que tuvo diez hijos. La primogénita, Sancha, se casará en 1660 con el duque de Benavente, Antonio Alonso Pimentel; el padre de este, Juan Alonso Pimentel, VII duque de Benavente, había conformado en 1612 una gran colección de «estatuas, en su mayor parte mármoles, alabastros, jaspes y bronces de origen clásico» (Morán y Checa 1985: 147), en el jardín de su palacio de Benavente, un "jardín arqueológico" como el de los Alcalá. Estando viudo, antes de este segundo matrimonio, había tenido Adán Centurión un hijo natural, Juan de Córdoba Centurión, al que nos referiremos luego. Algunos acontecimientos asemejan al marqués con el duque de Alcalá, aun siendo este de mayor prosapia y alcurnia, si bien Centurión entroncaba por línea materna con la importante familia andaluza de los Fernández de Córdoba. Ambos coincidían en la altivez, aunque ello era propio de la alta nobleza española de aquella época; también en los intereses eruditos; y en la pintura. Como algo más anecdótico, hemos de decir que ambos acudieron a la defensa de Cádiz contra los ingleses y neerlandeses, aunque el marqués lo hizo en 1626, cerca de 30 años después que el duque de Alcalá; también, en cierto modo, la vinculación con Cataluña, pues Centurión participó en la campaña de 1642 en el marco de las revueltas catalanas (Ballesteros 2002: 43-44).

Los intereses literarios de Adán Centurión se evidencian desde joven (Aguilar 1897) y la afición erudita queda avalada por el estudio de un tesoro de monedas ibéricas que había recuperado en Castulo (Cazlona, Jaén) en el año 1618 su cuñado, el III marqués de Camarasa, y que le regaló -Adán Centurión asimismo conformó un monetario, que le servía para sus estudios epigráficos y toponímicos (Ballesteros 2002: 60-63)-; el tratado lo escribió en 1623, bajo el título Discurso del marques de la Aula, y en él cita precisamente piezas conservadas en el monetario del III duque de Alcalá (Ballesteros 2002: 59-60). Solo se publicará en el siglo XIX, bajo el título Discurso sobre el vaso y medallas que se hallaron en Cazlona (Delgado 1871: 149-159), pero Adán Centurión le mandó el trabajo a Rodrigo Caro junto a una carta, conservada (Biblioteca Nacional, Mss/6334: 29$38 v$ ). El erudito utrerano es nexo entre ambos aristócratas, y el marqués del Aula debió asistir a algunas de las reuniones de la tertulia del duque en la Casa de Pilatos, lo que explicaría el conocimiento del monetario, de la biblioteca y el siguiente comentario de Francisco Pacheco, asiduo de la tertulia, según se dijo: «El Marques del Aula, i nuestro Duque de Alcala Virrei de Barcelona, que a juntado al exercicio de las Letras i Armas, el de la Pintura, como cosa digna de tan gran Principe» (Pacheco 1649: 113). Aunque la obra está editada posteriormente, el texto debió escribirse siendo el de Alcalá virrey de Cataluña, entre 1618 y 1622, antes de que el marqués del Aula heredara el título de marqués de Estepa. Esa vinculación a Sevilla del III marqués de Estepa se aminora a partir de 1626, año en que se casó en Granada y allí se quedó a vivir, convirtiéndose en ferviente defensor de las falsificaciones del Sacromonte granadino, los "libros plúmbeos" (por ejemplo, Barrios 2011), de los que incluso realizó una primera traducción (Ballesteros 2002: 67-78). Volverá a Estepa ya en 1644, y allí pasará la mayor parte de su tiempo hasta su muerte -aunque sin perder el vínculo con Granada-, dedicándose a su biblioteca, el estudio y sus aficiones eruditas. Su hijo natural Juan de Córdoba Centurión (1612-1665) (Jordán 2015) reunirá una singular colección arqueológica y epigráfica en la casa-palacio de Lora de Estepa, en lo que supone un proyecto excepcional en el marco coleccionista de la España del siglo XVII. En efecto, junto a una típica galería de estatuas clásicas, en número de seis, de las cuales una era de Italica y el resto de las tierras del marquesado, conformó un verdadero museo lapidario con inscripciones romanas, asimismo locales, y con una museografía muy avanzada para la época (Beltrán, 2015), junto a otros materiales arqueológicos, como cerámicas descubiertas en yacimientos asimismo ubicados en las tierras del marquesado. Todo ello lo justifica también Ballesteros (2002: 51-54) en clave política, como 

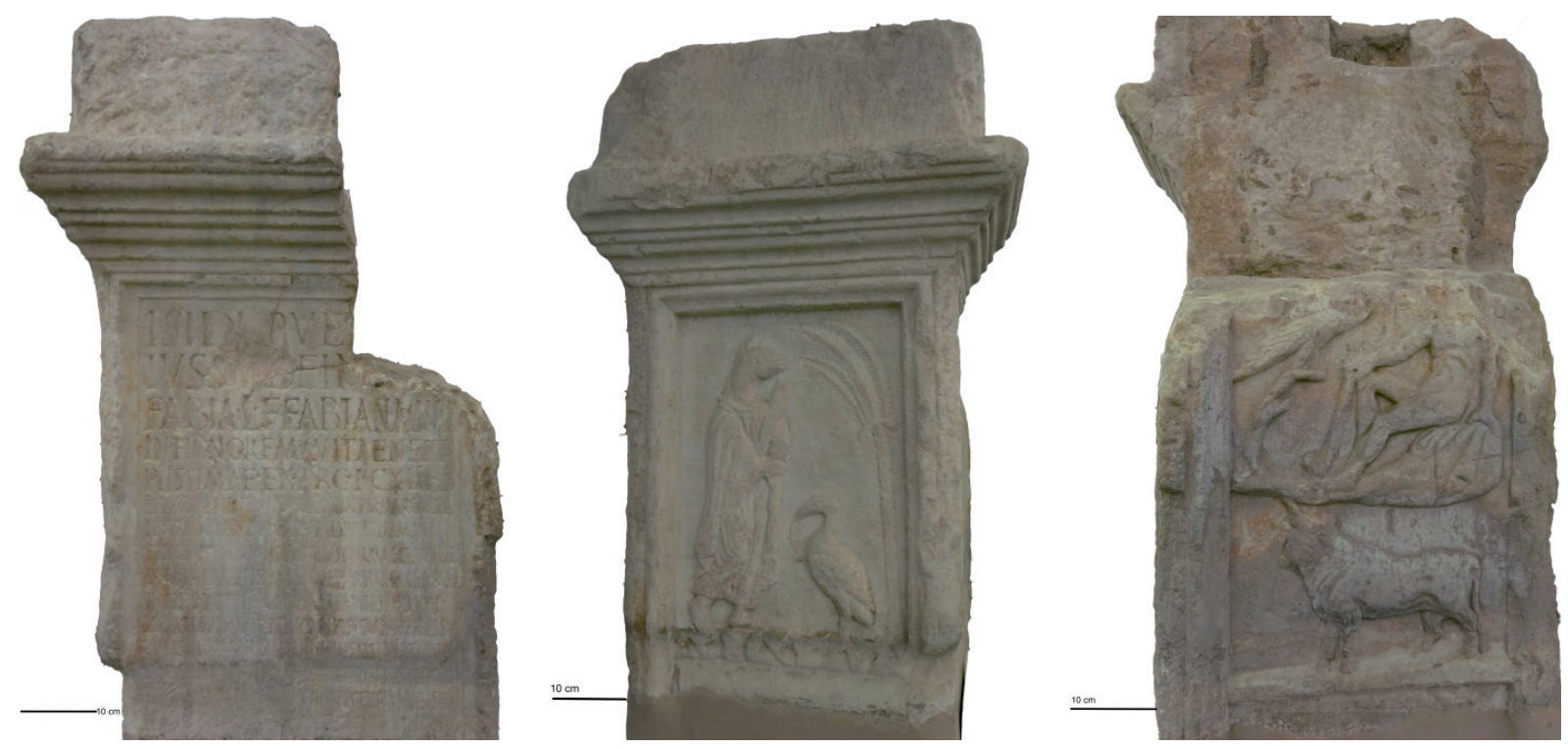

Figura 5. Pedestal isíaco de Acci (Guadix) (CILA Granada 122); mármol (dimensiones: 87 x 47 x 47 cm). Museo Arqueológico de Sevilla. A: frente; B: lateral derecho; C: lateral izquierdo.

un recurso para afianzar la cohesión del marquesado, que había sido creado en época del rey Carlos I, ya que remitiría al tema de los orígenes de aquel territorio en la antigüedad romana.

Por su vinculación con las tierras granadinas previa a su traslado de residencia, en el mismo año 1623 en que escribió el discurso sobre las monedas ibéricas, adquirió Adán Centurión el pedestal romano en Guadix y lo trasladó a Estepa. Normalmente se ha dicho que fue el hijo Juan de Córdoba quien regaló el pedestal al III duque de Alcalá (así lo recoge Emil Hübner en CIL II 3386), pero es un evidente error, no solo por la relación que tenía el padre con el duque de Alcalá y la Casa de Pilatos, a la que nos hemos referido, sino porque Juan de Córdoba en 1623 solo tenía once años. No sabemos en qué momento se lo donó, pero no debió ser muy alejado de esa fecha; Alcalá había vuelto de Cataluña en el año 1622 y en 1625 partió para Roma en la embajada ante el Papa, por lo que debió recibir el pedestal en esos años, que son precisamente cuando desarrolla su mayor actividad erudita en Sevilla. Rodrigo Caro incluyó un estudio documentado del pedestal granadino en su libro Veterum Hispaniae Deorum Manes sive reliquiae, que quedó inédito (Pascual 2002); había mandado una copia del texto a Ámsterdam para ser editado, pero nunca llegó a serlo, mientras que el manuscrito original quedó en su poder hasta su muerte, en que lo legó a la biblioteca del III marqués de Estepa. Este mismo se refiere a él en una de sus cartas dirigida a M. Vázquez Siruela como «el libro que me dejó Rodrigo Caro de los Dioses de España» (Ballesteros 2002: 280). Según se ha argumentado, es posible que el ejemplar manuscrito de Ámsterdam sea el que se conserva actualmente en la Biblioteca Bodleyana de Oxford (Ballesteros, 2000, Pascual 2002), que ha estudiado J. Alvar (2012: 120$121,2016)$ y que conserva los dibujos. Caro conoció otro trabajo que el marqués del Aula hizo sobre la inscripción, del que le indicó en una carta a José Pellicer que era de gran erudición (Aguilar 1897: 25-16).

En la Biblioteca Capitular y Colombina de Sevilla se conserva copia de un manuscrito titulado Declaracion de la inscripcion y figuras que se ven en un pedestal que Don Fernando Enríquez de Ribera Duque de Alcala mando traer de Guadix y poner en su casa de Sevilla. Año 1623, por Adam Centurion Marques de Lauula sucesor del de Estepa (BBC, MSS/57-3-33: 266r-285v), sin fecha, pero este encabezado es erróneo, pues ni el duque de Alcalá la trajo directamente desde Guadix, según se ha dicho, ni fue el marqués del Aula su autor, pues corresponde precisamente al estudio del mismo duque; es este quien indica al comienzo del texto que realiza el estudio con base en «el dibujo, y inscripcion, que VS me hizo merced de embiarme del Pedestal que mando traer de Guadix», por lo que es evidente que está dirigido al marqués, aunque parece asimismo que aún no tiene la pieza en su poder; se trata de una prolija y documentada memoria donde analiza tanto el epígrafe con la referencia a Isis y a las joyas, cuanto los relieves. 
En el mismo archivo sevillano se conserva otro manuscrito con el título Dibujos de don Fernando Enriquez de Ribera de un pedestal que trajo de Guadix (Biblioteca Capitular y Colombina, Mss/22/205: 289r$327 \mathrm{r}$ ), que termina indicando «Esta rubrica es del Ex ${ }^{\mathrm{mo}}$ $S^{\text {or }} D^{\mathrm{n}}$ Fernando Enriquez de Rivera, Tercer Duque de Alcala, y en quien acabo la Varonia de la Cassa; fue este Señor el que dedicado a las letras puso la celebre Liberia, y Adornos de las Cassas que tiene en Sevilla por los años de 1634» (Beltrán 2015: 80-82); el documento no tiene fecha y este año es el de su muerte, por lo que realmente no data su ejecución, que debió de ser bastante anterior, entre 1622 y 1625 .

\subsection{Otras inscripciones del III duque}

Antes hemos referido al menos cuatro placas sepulcrales que formaron parte de la colección del duque, ubicadas en el Camarín Grande, pero asimismo tuvo en su lapidario un par de grandes pedestales, que se conservan aún en la Casa de Pilatos. Están también expuestos actualmente en la galería abierta al Jardín Chico, junto a otras inscripciones, pero de las que no hay constancia de que pertenecieran a la colección del III duque; es probable que sean incorporaciones posteriores. Una de ellas, un altar sepulcral de caliza grisácea con la inscripción muy perdida (CILA Sevilla 141, fig. 67), sí está en la Casa de Pilatos con anterioridad a los comedios del siglo XIX, pues es citada en la obra manuscrita de José María López, fechada en 1848, pero que quedó inédita (Méndez Bejarano 1922: 382-383, n 1405): «...una de esas lápidas de sepulcros romanos, de jaspe oscuro, pero muy destruida y tan imposible de leer... Unicamente tiene las letras siguientes. H S E S:...:.: “Aquí está sepultado”..» (López 1848: 148, Beltrán, Gimeno y Mora en prensa).

Entre las piezas que sí sabemos que incorporó el III duque de Alcalá debemos referirnos, en primer lugar, a un pedestal honorífico (fig. 6), al que se refiere Rodrigo Caro a propósito de su reutilización en el castillo medieval de Utrera:

En la torre colateral de la torre mayor del omenage, que sale a la parte del mediodía del Castillo, estuvo una inscripcion, que yo siendo muchacho la vi; llevola el Doctor Arias Montano a una heredad suya, que tenia en Charco redondo junto a Sevilla, y de allí pienso, que se truxo a Sevilla, y està oy en las casas del Duque de Alcala, entre otros muchos pedaços de bonissima antigüedad, y tiene esto escrito, aunque dificultoso de leer (Caro 1634: $144 \mathrm{v}-145 \mathrm{r})$.

Teniendo en cuenta que Arias Montano murió en 1598 , la fecha de la incorporación a la colección ducal fue posterior a esta (Méndez Rodríguez 2005: 210). Corresponde a un gran pedestal de estatua, elaborado en mármol blanco de grano grueso y tono rosado, que debe de corresponder, de visu, a las canteras de Almadén de la Plata (Taylor 2015). En efecto, la larga inscripción, elaborada en letras librarias, está muy desgastada y tiene una fractura longitudinal que afecta a la parte derecha de la pieza, y a la inscripción en el inicio de todas las líneas; corresponde a la estatua honorífica dedicada por Cesia Senilia al senador Marco Cutio Prisco, relacionado con las importantes familias béticas de los Messi y los Aemilii, que procede de la ciudad romana de Siarum (La Cañada, Utrera) y se fecha en época antoniniana (CIL II 1283; CILA Sevilla 933).

El otro soporte (fig. 7), que asimismo se conserva actualmente en la Casa de Pilatos, es un pedestal de similar forma, cuadrangular y tripartito monolítico, elaborado también en mármol blanco de Almadén de la Plata, que presenta en este caso unas típicas venillas rojas. Procede de Sevilla, donde se sitúa la romana Hispalis, y de nuevo es R. Caro quien afirma en un manuscrito que fue descubierta «en las çanjas que poco ha se hizieron para el colegio de San Alberto en la parroquia de San Isidro» (recogido en CIL II 1179). Aunque también se refiere a ella en las Antiguedades de Sevilla (Caro, 1634: 66r), desconocemos en qué momento exacto escribió el erudito la otra cita manuscrita y cuándo consiguió el duque de Alcalá la pieza para su colección. No obstante, el convento de San Alberto de Sicilia en Sevilla, con el colegio anexo, de la orden de los carmelitas, recibió una donación de Bernardina de Salazar y obtuvo la licencia del arzobispado hispalense para su construcción en 1602, por lo que en los años siguientes debió descubrirse el pedestal en aquellos trabajos. La estatua está dedicada por los confectores aeris a Tito Flavio Polycriso, liberto del emperador Tito, que gestionaba las minas de Sierra Morena como procurator Montis Mariani (CILA Sevilla 25).

\subsection{Varia anticuaria}

En los inventarios citados que refieren la colección de Fernando Enríquez (Brown y Kagan 1987; Mallén 2017), a pesar de la parquedad en las descripciones, puede llamarse la atención sobre determinadas piezas 


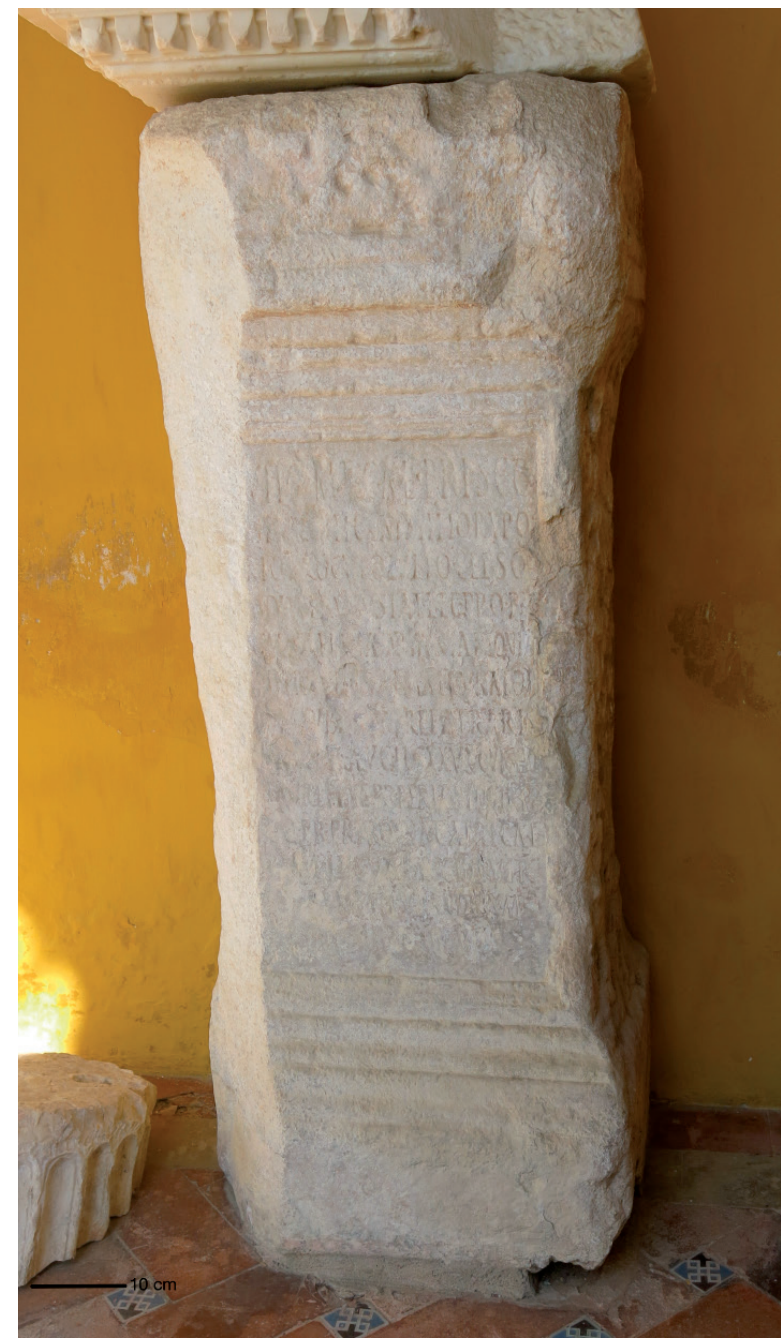

Figura 6. Pedestal de M. Cutio Prisco, de Siarum (Utrera) (CILA Sevilla 933); mármol (dimensiones: 151 x 54 x $38 \mathrm{~cm}$ ). Casa de Pilatos, Sevilla.

que completan su gusto anticuario y de interés por la Antigüedad y sus restos, de matriz manierista, que realmente acompañó al III duque a lo largo de su vida, pero especialmente en las primeras etapas ya indicadas. Eran piezas modernas que recreaban lo antiguo, que eran elaboradas "a la antigua", por lo que quizás se pensaba que eran tales o que tenían un cierto carácter exótico o excepcional, y que estaban colocadas en el Camarín Grande. Dejando aparte las propias piezas romanas, entre las que se incluyen lógicamente, aparte de las inscripciones descritas, las monedas de su colección, así como «todas las urnas de piedra, de bronce y de barro» (Mallén 2017: 126) o «168. dos botijuelas de barrochatas antiguas que se hallaron en Aguilar. 169. quatro

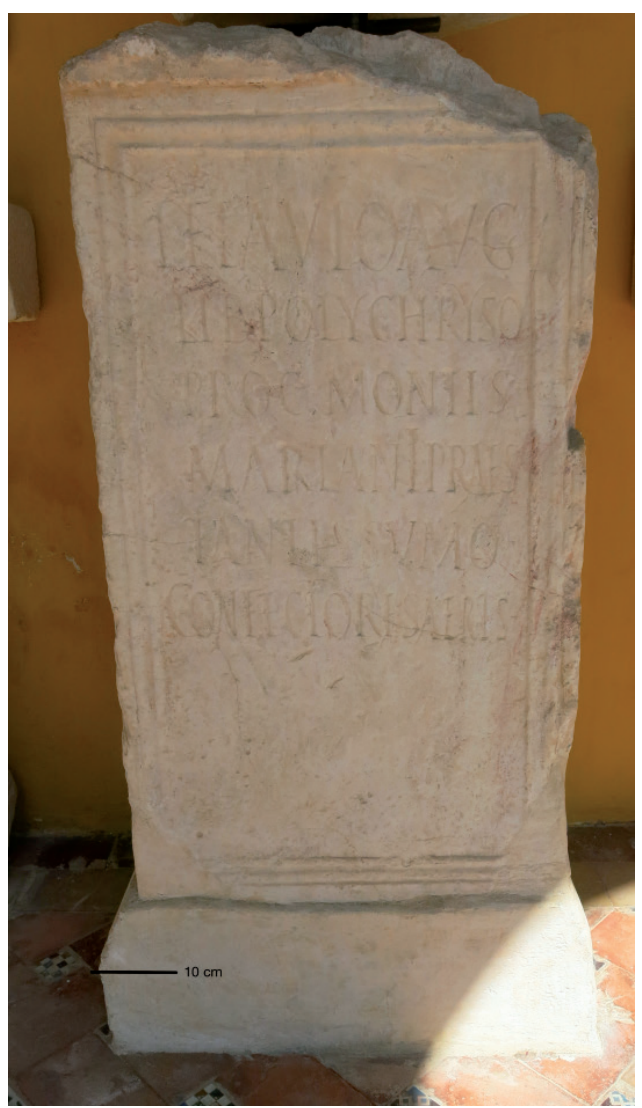

Figura 7. Pedestal de T. Flavio Polycriso, de Hispalis (Sevilla) (CILA Sevilla 25); mármol (dimensiones: 126 x 60,5 x 52,5 cm). Casa de Pilatos, Sevilla.

candiles de barro antiguos. 170 . cinco lacrimatorios de vidrio antiguos. 171. cinco losetas de marmol antiguas con inscripciones de Sepulcro. 172. un pato de bronce antiguo q sirve de candil. 173. Una caveça de marmol blanco antigua. 174. una loçeta de marmol blanco como caseta pa moler antigua» (Brown y Kagan 1987: 254).

En otro inventario de 1640 se dice: «Sinco lacrimatorios de bidro se quebraron» (Mallén 2017: 129), que corresponden a los referidos en el $n^{\circ} 170$.

Según se refirió ya, el Camarín Grande albergaba también casi un centenar de pequeños bronces que representaban a personajes de la Antigüedad y, en menor cantidad, de época moderna, dentro de un interés por este tipo de piezas dentro de las cámaras de maravillas 
renacentistas (Coppel 1993). Los bronces fueron trasladados en su mayor parte a Madrid, a las colecciones de los Medinaceli, y hoy se conservan algunos en el Museo Arqueológico Nacional; de esta colección Medinaceli reprodujo B. de Montfaucon (1722) siete lucernas de bronce, que dibujó en su monumental obra, de formas caprichosas y grotescas, y que, con excepción de una con el asa decorada con cabeza de grifo, datada entre los siglos IV-VII d.C. (Mora 2020: 103), son obras modernas, dos de ellas «catalogadas como falsificaciones renacentistas de un taller de Padua» (Mora 2020: 110); no sabemos con seguridad si correspondían a las de la colección del III duque de Alcalá, pero se tratan de lucernas apropiadas al gusto manierista de inicios del siglo XVII.

Existían asimismo pinturas que hacían referencia a la Antigüedad, como las «dos piedras negras pintadas, una batalla y el rovo de Proçerpina» (Mallén 2017: 125, Brown y Kagan, 1987: 252, n 42), o los «tres quadros de ruyna medianos de Roma» (Mallén 2017: 123). De carácter más singular es el «142. clavo de la Rotunda de Roma» (Brown y Kagan 1987: 254), que desapareció tras el traslado del duque a Nápoles, según se refiere en el inventario de piezas perdidas, de 1640: «Un clabo de bronce antiguo que abrá sido del techo de la rotunda de Roma que pesaria seis libras» (Mallén 2017: 128). Como indica V. Lleó: «Para realizar su baldaquino de San Pedro, iniciado en 1624, Bernini había arrancado el casetonado de bronce del pórtico del Panteón, lo que hace plausible que se vendieran como souvenirs sus clavos» (Lleó 1996: 825, nota 9); dejando aparte su autenticidad, la justificación de su presencia en la colección se vincularía a su estancia en Roma, cuando fue embajador ante el Vaticano, entre 1625 y 1626.

Según ha destacado el propio Lleó (1996), José Maldonado y Saavedra ilustra la tradición, recogida por su sobrino, el ya referido cronista sevillano Diego Ortiz de Zúñiga (1636-1680), de que en la colección sevillana del duque se encontraba la urna que había contenido las cenizas de Trajano en Roma:

Esta urna de alabastro con las cenizas del Emperador Trajano recogio un ciudadano de Roma el qual se la presentó a Don Pedro Afan de Ribera, el doctissimo Duque de Alcala en el año de 1630, siendo embaxador de Roma, el qual la enbio a Sevilla con otras antiguedades que enbio a ella a Don Juan de Arroyo, Alcaide de sus palacios, el qual la recibio y puso en la librería que en aquel palacio se conserva. Sucedió al año delante de [1]636, con la muerte del Duque de Alcala, haziendose almoneda de los bienes sueltos que en él havia, que una criada robó la urna y tiró las cenizas al jardín de la Casa de Pilatos, aunque se recuperó la pieza, que «al presente esta en la librería la dicha urna que es de alto de media vara, istriada por de fuera» (Ortiz 1796: III, 297, Lleó 1996: 825, lám. 1).

V. Lleó ya indicó los evidentes errores, pues la embajada no correspondió al año 1630, ni el duque murió en 1636, así como si podría identificarse esa urna con «un baço de pórfido con unos grifos de plata por asas» (Mallén 2017: 125) que se encontraba en el Camarín Grande, aunque lo plantea con prudencia (Lleó 1996: 824-825).

Por otro lado, opinaba que la descripción y el dibujo de la pieza

recuerdan a otros ejemplos de escultura decorativa all'antica en la que se especializaban los talleres romanos... Solo cabe especular que, conocedor algún marchante romano de la procedencia sevillana del Duque de Alcalá, hubiese decidido 'adornar' la pieza con una fantástica vinculación con el optimus princeps, para hacerla así más atractiva (Lleó 1996: 825).

Era, por tanto, un ejemplo más del coleccionismo manierista y erudito del duque, pues vinculaba a Trajano lógicamente con su lugar de nacimiento, Italica, tan cercana a Sevilla y a la que había cantado Rodrigo Caro en su Canción a las Ruinas de Italica.

Finalmente, cabe referir otra pieza singular que asimismo se situaba en el Camarín Grande en la Casa de Pilatos: «91. un lienço grande $q$ vino de rroma con $g^{\text {on }}$ grande dorada de un esponsaliçio y una tabla debajo con una iscripcion de lienzo» (Brown y Kagan 1987: 254), que también es descrita como «un lienço de los desposorios de los romanos» (Mallén 2017: 125). Es, por tanto, otra pieza traída desde Roma en el período de la embajada, que conocemos mejor porque a ella dedica F. Pacheco en su obra El arte de la Pintura un largo comentario (Pacheco 1649: 33):

...una pintura nuevamente hallada en Roma, que solo bastava por ilustre exemplo de duracion. Cuya descripción me envio el Exelentiss. S. Duque de Alcala, que la hizo copiar cuando fue por Embaxador del Réi Filipo 4. a dar la obediencia a la Santidad de Vrbano otavo, que dize desta manera.

[en el lateral derecho se dice: "Discurso del Duque"]

La historia es un sponsalicio donde se ven los novios medio desnudos sentados sobre la cama o Toro genial, i sentado en tierra arrimado a ella, asiste el Genio de las bodas, coronado de flores.

A la parte izquierda están los que ofrecen el incienso para el Sacrificio de aquella accion, ayudada 
de unas Citaristrias. A la parte derecha están calentando el agua lustral para los pies de la esposa.

La pintura es de colores al fresco en una pared. Hallosse en Roma siendo Pontifice Clemente VIII abriendo unos cimientos el Cardenal Aldobrandino en un jardin, o viña que tiene cerca del Palacio de Monte Cavallo. I sacando la pared entera, se acomodo en un corredor del mismo jardín donde oi esta, defendido por una puerta de madera. Cuyos colores, cuando se descubrió, estavan vivos como los que se pudieron poner.

La copia desta pintura, que tendrá de ancho casi tres varas, i dos de alto, mandò hazer del Duque de Alcala, hallándose en Roma el año 1625. i la truxo a sus casas de Sevilla.

No ai razón de cuando se pintó, pero supuesto que no es moderna no puede tener menos que mil, i trezientos años de antigüedad. Antes que las artes descaeciesen con el Imperio: que desde que se passò a Constantinopla, hasta que Micael Angel, i Rafael resucitaron la pintura, no se halla de aquel medio tiempo cosa que no sea abominable de pintura, $\mathrm{i}$ scultura.

Se trata, pues, de un lienzo que copia la famosa pintura mural romana de Le Nozze Aldobrandini, elaborada al fresco; descubierta en 1601 en Roma, había sido adquirida por el cardenal Pietro Aldobrandini (Palma 2007: 81-82). Fue sacada y colocada en su villa suburbana de Magnanapoli, en el Quirinal, «en un corredor del mismo jardín donde oi esta, defendido por una puerta de madera», según decía el mismo duque de Alcalá en su carta a Pacheco. Restaurada en 1605-1609 por Federico Zuccari, actualmente se conserva en la Bibliotheca Apostolica Vaticana. El estudioso Cassiano dal Pozzo encargó en 1627 un grabado a Pietro da Cortona, como ejemplo de su impacto entre artistas, coleccionistas y anticuarios, pero la copia realizada por Alcalá para Sevilla es anterior, de 1625. Como indica Pacheco el lienzo medía tres varas de anchura y 2 varas de altura, es decir unos $1.6 \mathrm{~m}$ de altura x $2.4 \mathrm{~m}$ de anchura, acorde con las dimensiones originales de $1.20 \times 2.60 \mathrm{~m}$, por lo que sería una copia casi al tamaño natural; la mayor altura puede deberse a que - como se decía en uno de los inventarios- tenía debajo de la pintura una inscripción. Reproduce Pacheco la carta del mismo duque desde Italia, donde le hacía la descripción e interpretación de las escenas, con el tema de una boda. Es muy posible que Fernando Enríquez en su estancia romana, además de la adquisición de cuadros, hubiera dedicado buena parte del tiempo a ver ruinas romanas y colecciones, así como a tratar con anticuarios y estudiosos, lo que le llevó a la adquisición de estas piezas "curiosas"; asimismo, adquirió en Roma seguramente el decenpondium al que ya nos referimos.

\section{CONCLUSIONES}

La deriva coleccionista del III duque de Alcalá va desde los intereses anticuarios al coleccionismo de pinturas, que corresponde a un proceso general para la nobleza española, acorde además con los gustos de la monarquía de los Austrias en España durante el siglo XVII (Morán y Checa 1985). En el caso concreto de Fernando Enríquez hay que vincularlo también a sus estancias en Italia, primero como embajador en Roma y luego como virrey en Nápoles y Sicilia, en lo que ha sido denominado como una distorsión del esquema manierista hacia un proyecto barroco, y en el que «la modernidad de la afición del III duque de Alcalá por la pintura no era una cuestión simplemente cuantitativa, como ocurre, por ejemplo, en el caso de los Medina Sidonia; sino, sobre todo, una inclinación perfectamente delimitada por un gusto estético especifico» (Urquízar 2007: 128). Ello queda en evidencia en el repaso de los inventarios conservados, en los que se citan especialmente cuadros (Brown y Kagan 1987, Mallén 2017). Suponía un cambio importante con respecto a los intereses coleccionistas de su antecesor, su tío abuelo, el I duque de Alcalá, Per Afán de Ribera, que se centró en el coleccionismo de estatuas romanas, atesoradas en Italia durante su largo virreinato en Nápoles.

Por el contrario, el interés por la Antigüedad y las antigüedades de Fernando Enríquez no se basa en las esculturas clásicas, sino -sobre todo, en un primer momento de su vida- en el cultivo de las artes y las letras, con la puesta en marcha de una importante tertulia o academia, la más importante sevillana de los primeros decenios del siglo XVII. Además, desarrolló un interés por la erudición y la anticuaria, vinculado a la figura de Rodrigo Caro; ello se plasma en su monetario, poco conocido, y en otras colecciones de piezas menores bronces de pequeño tamaño-, así como en sus piezas epigráficas, su lapidario, corto en piezas, pero singulares muchas de ellas. A las ya tratadas (España-Chamorro 2019), se suman las analizadas ahora, en concreto, las tres copias de epígrafes obtenidas en Tarragona durante su estancia en Cataluña como virrey, así como los tres pedestales procedentes de Guadix, Utrera y Sevilla. Sobresale especialmente el fenómeno de las copias epigráficas, acorde con el espíritu coleccionista del duque, que también ordenó copiar a tamaño natural la pintura de $L e$ Nozze Aldobrandini en Roma, así como el pedestal de 
Guadix, un regalo del III marqués de Estepa -otro noble andaluz culto y erudito-, por la singularidad que presentaban el epígrafe y los relieves de tema egipcio, al que el propio Fernando Enríquez dedicó un trabajo. Por tanto, a raíz del estudio de su lapidario se enriquece nuestra visión de este personaje en el terreno de la cultura española y andaluza de la primera mitad del siglo XVII, al que tradicionalmente se le recuerda por su gran biblioteca, pero que asimismo incorpora otros valores de erudición dignos de ser tenidos en cuenta.

\section{AGRADECIMIENTOS}

Mi agradecimiento a la Fundación Ducal Medinaceli por las facilidades dadas para la realización del estudio y fotografías que van en este trabajo, y muy especialmente a D. Javier Barbasán, conservador de la colección arqueológica expuesta en la Casa de Pilatos. Este trabajo se hace en el marco de las actividades del Grupo de I+D "Historiografía y Patrimonio Andaluz" (HUM 402), del P.A.I., adscrito al Dpto. de Prehistoria y Arqueología de la Universidad de Sevilla

\section{BIBLIOGRAFÍA}

Aguilar y Cano, A. (1897): El marqués del Aula. Los ingenios de las flores de poetas ilustres de España (Estudios bibliográficos). Sevilla, E. Rasco.

Alvar Ezquerra, J. (2012): Los cultos egipcios en Hispania. Franche-Comté, Presses Universitaires.

Alvar Ezquerra, J. (2016): “Agua fresca para Avita y joyas de inmortalidad para Isis (CIL II 3386)". Dialogues d'Histoire Ancienne 42, 1: 201-218.

Atencia Páez, R. (1993): “Aportaciones de la historiografía al estudio y localización de las ciudades romanas de Andalucía”, en J. Beltrán y F. Gascó (eds.), La antigüedad como argumento. Historiografía de arqueología e historia antigua en Andalucia: 85-103. Sevilla, Universidad de Sevilla.

Ballesteros Sánchez, J. R. (2000): “El libro más perdido de esta biblioteca perdida". Los papeles mojados de Río Seco 3: 24-25.

Ballesteros Sánchez, J. R. (2002): La antigüedad barroca. Libros, inscripciones y disparates en el entorno del III Marqués de Estepa. Sevilla, Diputación Provincial de Sevilla.

Barrios Aguilera, M. (2011): La invención de los libros plúmbeos. Fraude, historia y mito. Granada, Universidad de Granada.
Beltrán Fortes, J. (1994): “Altares visigodos, reutilizaciones paganas (I)”, en P. Sáez y S. Ordóñez (eds.), Homenaje al Profesor Presedo: 785-810. Sevilla, Universidad de Sevilla.

Beltrán Fortes, J. (2003): "La antigüedad romana como referente para la erudición española del siglo XVIII", en J. Beltrán, B. Cacciotti, X. Dupré y B. Palma (eds.), Illuminismo e Ilustración. Le antichità e $i$ loro protagonisti in Spagna e in Italia nel XVIII secolo: 47-64. Roma, L'Erma di Bretschneider.

Beltrán Fortes, J. (2009): "Caro, Rodrigo", en Diccionario Biográfico Español de la Real Academia de la Historia tomo XI: 549-552. Madrid, Real Academia de la Historia.

Beltrán Fortes, J. (2010): "Brillo y color de joyas en la estatuaria hispanorromana a través de las inscripciones”, en V. Brinkmann y M. Bendala (eds.), El color de los dioses. El colorido de la estatuaria antigua: 269-277. Madrid, Comunidad de Madrid.

Beltrán Fortes, J. (2015): "La singular colección arqueológica de Juan de Córdoba, formada en Lora de Estepa (Sevilla) durante el siglo XVII", en Actas de las II Jornadas de Historia y Patrimonio. Lora de Estepa: 47-90. Sevilla, Ayuntamiento de Lora de Estepa.

Beltrán Fortes, J. (2017a): "Las antigüedades en los círculos artísticos y anticuarios de la Sevilla de Juan de Arguijo", en E. Peñalver y M. L. Loza (coords.), Juan de Arguijo y la Sevilla del Siglo de Oro: 125145. Sevilla, Editorial Universidad de Sevilla.

Beltrán Fortes, J. (2017b): "Retratos masculinos en colecciones arqueológicas en Andalucía durante la Edad Moderna", en M. Clavería (coord.), Viri Antiqui: 65-77. Sevilla, Editorial Universidad de Sevilla.

Beltrán Fortes, J.; Gimeno Pascual, H. y Mora Serrano. B. (en prensa): Sobre inscripciones y monedas. El anticuario Francisco Xavier Delgado Jurado en los primeros decenios del siglo XIX. Schedae epigráficas sevillanas y monetario. Sevilla, Editorial Universidad de Sevilla.

Beltrán Fortes, J. y Loza Azuaga, M. L. (2020): Provincia de Cádiz (Hispania Vlterior Baetica), Corpus Signorum Imperii Romani-España, I, 8. CádizTarragona, Editorial Universidad de Cádiz e ICAC.

Beltrán Fortes, J. y Loza Azuaga, M. L. (en prensa): "Dos estatuas de ninfas de época renacentista en el jardín del palacio del I duque de Alcalá en Bornos (Cádiz, España)", en Convegno Internazionale "Roma e la Spagna in dialogo. Interpretare, disegnare, collezionare l'antichità classica nel Rinascimiento". Roma (2019). 
Beltrán Fortes, J. y López Rodríguez, J. R. (eds.) (2003): El museo cordobés de Pedro Leonardo de Villacevallos. Coleccionismo arqueológico en la Andalucía del siglo XVIII. Málaga-Madrid, Universidad de Málaga y Real Academia de la Historia.

Bonneville, J.-N. (1981): “A propos del'explotitation des livres anciens par E. Hübner: les Antiguedades de Ambrosio de Morales (1575)", en R. Étienne (coord.), Épigraphique Hispaniqie. Problèmes de méthode et d'edition: 86-83. Paris, E. de Boccard.

Brown, J. (1995): Imágenes e ideas en la pintura española del Siglo de Oro. Madrid, Alianza.

Brown, J. y Kagan, R. (1987): “The Duke of Alcalá: His Collection and its Evolution". Art Bulletin 692: 231-255. https://doi.org/10.1080/00043079.1987 .10788422 .

Caro, R. (1622): Antigüedad de Utrera. Relación de las inscripciones y antigüedad de la Villa de Utrera. Biblioteca Nacional, Mss/1743.

Caro, R. (1634): Antiguedades y Principado de la Ilustrissima Ciudad de Sevilla y Chorografia de su Convento Iuridico, o Antigua Chancilleria. Sevilla, Andres Grande.

Caro, R. (1978): Dias geniales o lúdricos (ed. a cargo de J.-P. Etienvre). Madrid, Espasa-Calpe.

Caro, R. (sin fecha): Varones insignes en letras naturales de la ilustrísima ciudad de Sevilla. Biblioteca Nacional, Mss/9575.

CIL II = Hübner, E. (1869): Corpus Inscriptionum Latinarum. II. Inscriptiones Hispaniae Latinae. Berolini, apud Georgium Reimerum.

CILA Granada = Pastor Muñoz, M. (2002): Corpus de inscripciones latinas de Andalucía.IV: Granada. Sevilla, Junta de Andalucía.

CILA Sevilla = González Fernández, J. (1991-1996): Corpus de inscripciones latinas de Andalucía. II: Sevilla. Sevilla, Junta de Andalucía.

Coppel, R. (1993): "El coleccionismo de pequeños bronces del Renacimiento en España: origen y colección del Museo Arqueológico". Archivo Español de Arte 66: 373-392.

Delgado Martínez, A. (1875): Nuevo Método de clasificación de las medallas autónomas de España, tomo I. Sevilla, Antonio Izquierdo y Sobrino.

Di Dio, K. H. y Coppel, R. (2013): Sculpture Collections in Early Modern Spain. Abingdon, Ashgate.

Domergue, C. y Étienvre, J.-P. (1971): “Á propos d'une inscription des 'Dias Geniales' de Rodrigo Caro: mystification ou fantaisie d'humaniste?'. Mélanges de la Casa de Velázquez 7: 381-395.
Engel, A. 1903: "Inventaire de la Casa de Pilatos en 1752”. Bulletin Hispanique 5, 3: 259-271.

España-Chamorro, S. (2019): "El lapidario del III Duque de Alcalá de los Gazules. Apuntes sobre CIL II, 4962, CIL II, 1211 y otras noticias epigráficas”. Anuari de Filologia. Antiqua et Mediaevalia 9.1: 73-79. https://doi.org/10.1344/AFAM2019.9.1.6.

Elliot, J. (1963): Revolt of the Catalans. Cambridge, University Press.

Fernández Lacomba, J. (2008): "El tercer duque de Alcalá”, en F. Amores, J. Beltrán y J. Fernández Lacomba (eds.), El rescate de la Antigüedad clásica en Andalucía: 161. Sevilla, El Viso.

Gestoso Pérez, J. (1910): Curiosidades antiguas sevillanas: estudios arqueológicos. Sevilla, El Universal.

Gimeno Pascual, H. y Stylow, A. U. (2003): "Las inscripciones", en J. Beltrán y J. R. López (eds.), El museo cordobés de Pedro Leonardo de Villacevallos. Coleccionismo arqueológico en la Andalucía del siglo XVIII: 149-218. Málaga-Madrid, Universidad de Málaga y Real Academia de la Historia.

González Moreno, J. (1969): Don Fernando Enríquez de Ribera, tercer duque de Alcalá de los Gazules (1583-1637). Estudio biográfico. Sevilla, Imprenta Municipal.

Jordán Fernández, J. A. (2015): “De una humilde cuna a las más altas magistraturas en la corte de Felipe V: don Juan de Córdoba Centurión (1612-1665)", en Actas de las II Jornadas de Historia y Patrimonio. Lora de Estepa: 9-44. Sevilla, Ayuntamiento de Lora de Estepa.

Lleó Cañal, V. (1979): Nueva Roma: mitología y humanismo en el Renacimiento sevillano. Sevilla, Diputación Provincial de Sevilla.

Lleó Cañal, V. (1987): “El jardín arqueológico del primer Duque de Alcalá". Fragmentos 11: 21-32.

Lleó Cañal, V. (1998): La Casa de Pilatos. Madrid, Electa.

Lleó Cañal, V. (2017): La Casa de Pilatos. Biografía de un palacio sevillano. Sevilla, Editorial Universidad de Sevilla.

López Rodríguez, J. R. (2010): Historia de los museos de Andalucía. 1500-2000. Sevilla, Editorial Universidad de Sevilla.

López Torrijos, R. (1999): "El techo de la casa del poeta Juan de Arguijo", en Velázquez y Sevilla. Estudios: 182-196. Sevilla, Junta de Andalucía.

Loza Azuaga, M. L. y Romero Pérez, M. (2014-2015): "Breves notas sobre el urbanismo de Antikaria (Antequera, Málaga). A propósito del hallazgo de un togado en las inmediaciones de la Colegiata de Santa María La Mayor". Mainake 35: 157-180. 
Mallén Herráiz, D. (2016): “Las esculturas de Giambologna en la colección del III Duque de Alcalá de los Gazules", en A. Lobato, E. de los Reyes, I. Pereira y C. García (eds.), El legado hispánico: manifestaciones culturales y sus protagonistas: I, 295-313. León, Universidad de León.

Mallén Herráiz, D. (2017): "La colección artística del III Duque de Alcalá: nuevos documentos". Ars Longa 26: 111-130.

Mallén Herráiz, D. (2018a): “La colección artística y literaria del III duque de Alcalá durante el virreinato de Nápoles (1629-1631)", en M. Gómez-Ferrer e Y. Gil (eds.), Ecos culturales, artísticos y arquitectónicos entre Valencia y el Mediterráneo en época moderna: 249-268. Valencia, Universidad de Valencia.

Mallén Herráiz, D. (2018b): "La biblioteca del III duque de Alcalá y el ambiente intelectual sevillano en el siglo XVII", en A. Cañestro (ed.), Scripta artium in honorem prof. José Manuel Cruz Valdovinos: 387-404. Alicante, Universidad de Alicante.

Méndez Bejarano, Mario (1922): Diccionario de escritores, maestros y oradores naturales de Sevilla y su actual provincia. Sevilla, Girones.

Méndez Rodríguez, L. (2000): “Lecturas y miradas de un humanista. La colección del canónigo Luciano de Negrón". Archivo Hispalense 251: 115-138.

Méndez Rodríguez, L. (2005): Velázquez y la cultura sevillana. Sevilla, Universidad de Sevilla y Fundación Focus-Abengoa.

Montfaucon, B. de (1722): L'Antiquité expliquée et représentée en figures, t. V. París, F. Delaulne et alii.

Montoto Rautenstrauch, L. (1915): El Licenciado Rodrigo Caro. Varones insignes en letras naturales de la ilustrísima ciudad de Sevilla. Epistolario. Sevilla, Real Academia Sevillana de Buenas Letras.

Mora, G. (2020): "Bernard de Montfaucon, Manuel Martí y la representación de las antigüedades de España”, en D. Moreau y R. González (eds.), Academica Libertas. Essais en l'honneur du professeur Javier Arce: 97-115. Paris, Brepols Publishers.

Mora Serrano, B. (2004): “Antonio Delgado y Hernández", en Pioneros de la Arqueología en España del siglo XVI a 1912: 283-288. Alcalá de Henares, Comunidad de Madrid.

Morán Turina, M. (2010): La memoria de las piedras. Anticuarios, arqueólogos y coleccionistas de antigüedades en la España de los Austrias. Madrid, Centros de Estudios Europa Hispánica.

Morán, M. y Checa, F. (1985): El coleccionismo en España. De la cámara de maravillas a la galería de pinturas. Madrid, Cátedra.
Morejón Ramos, J. A. (2009): Nobleza y Humanismo. Martín de Gurrea y Aragón. La figura cultural del IV duque de Villahermosa (1526-1581). Zaragoza, Institución Fernando El Católico.

Ortiz de Zúñiga, D. (1796): Anales Eclesiásticos y Seculares de la Muy Noble y Muy Leal Ciudad de Sevilla, Metropoli de Andalucia, t. IV. Madrid, Imprenta Real.

Pacheco, F. (1649): Arte de la Pintura, su antigüedady grandezas. Sevilla, Simon Fajardo.

Pacheco, F. (1985): Libro de Descripción de Verdaderos Retratos de Ilustres y Memorables Varones (edición e introducción de P. M. Piñero y R. Reyes). Sevilla, Diputación Provincial de Sevilla.

Palma Venetucci, B. (2007): Dallo scavo al collezionismo, un viaggio nel passato dal Medioevo all'Ottocento. Roma, De Luca.

Panzram, S. (2009): "Philipp II. Kam nur bis Sevilla... Der 'Arco de los Gigantes' in Antequera", en Espacios, usos y formas de la Epigrafia hispana en épocas antigua y tardoantigua. Homenaje al Dr. Armin U. Stylow, Anejos de AEspA XLVIII: 247-258. Mérida, Instituto de Arqueología del CSIC.

Pascual Barea, J. (2002): “Veterum Hispaniae Deorum manes sive reliquiae: noticias del tratado de Rodrigo Caro sobre la religión antigua en Hispania", en Nova et Vetera. Nuevos horizontes de la Filología Latina: vol. II, 1049-1064. Madrid, Sociedad de Estudios Latinos.

Peñalver Gómez, E. y Loza Azuaga, M. L. (coords.) (2017): Juan de Arguijo y la Sevilla del Siglo de Oro. Sevilla, Editorial Universidad de Sevilla.

Rodríguez Marín, F. (1903): Noticia biográfica de Don Fernando Afán de Ribera y Enríquez, IV Marqués de Tarifa. Sevilla, El Mercantil Sevillano.

Rubio Lapaz, J. (1993): Pablo de Céspedes y su circulo. Humanismo y Contrarreforma en la cultura andaluza del Renacimiento al Barroco. Granada, Universidad de Granada.

Serrano Ramos, E. y Atencia Páez, R. (1981): Inscripciones latinas del Museo de Málaga. Madrid, Ministerio de Cultura.

Trunk, M. (2001): "La colección de esculturas antiguas del primer duque de Alcalá de la Casa de Pilatos en Sevilla", en El coleccionismo de escultura clásica en España: 89-10. Madrid, Museo de El Prado.

Trunk, M. (2002): Die "Casa de Pilatos" in Sevilla. Studien zu Sammlung, Aufstellung und Rezeption antiker Skulpturen im Spanien des 16. Jhs. Mainz am Rhein, Ph. von Zabern. 
Trunk, M. (2013): "Novedades de la Colección de los duques de Alcalá y Medinaceli", en Escultura Romana en Hispania, VII, pp. 89-100. Santiago de Compostela, Universidad de Santiago.

Trunk, M. (en prensa): "Il viceré napoletano Per Afán di Ribera, duca di Alcalá, collezionista antichità", en
Convegno Internazionale "Roma e la Spagna in dialogo. Interpretare, disegnare, collezionare l'antichità classica nel Rinascimiento". Roma (2019).

Urquízar Herrera, A. (2007): Coleccionismo y nobleza. Signos de distinción social en la Andalucía del Renacimiento. Madrid, Marcial Pons. 
